\title{
The Impact of Credit Rating on Innovation in a Two-sector Evolutionary Model
}

\author{
Pascal Aßmuth
}




\title{
The Impact Of Credit Rating On Innovation In A Two-Sector Evolutionary Model
}

\author{
Pascal Aßmuth*
}

October 2015

\begin{abstract}
Empirical evidence shows that innovative firms are often more constrained in obtaining external funds than less innovative firms. Explanations are based on the uncertain outcome and high costs of R\&D effort. When providing credit, the lender assesses the creditworthiness of the borrower. She relies on financial data and market analysis. The financial data analysis reveals costs and the market outlook is linked to the uncertainty of future profitability. In this paper we examine whether the credit assessment behaviour of banks hurts firms of a more innovative sector more and how this affects long term innovative success and economic development. We use an evolutionary approach à la Nelson and Winter but with two sectors. A bank provides credit and supplies it to single firms based on a rating. We illuminate the impact of rating process characteristics on the long term outcome. When the bank does not distinguish for sector-specific features, such as risk and market outlook, the high-tech sector benefits over-proportionally because the surviving firms have a high profitability and further innovations are more likely. The way that the bank forms expectations about the market outlook influences the allocation of credit between sectors. The innovative sector is supplied more credit if the market outlook is assessed in a rather conservative fashion. The impact on aggregates however, is limited because the bank uses other pieces of information as well.
\end{abstract}

Keywords: Innovation, Financial Constraints, Industrial Evolution JEL-Classification: G32, O16, O33

* Bielefeld Graduate School of Economics and Management (BiGSEM), Center for Mathematical Economics, Bielefeld University, and Université Paris 1 Panthéon-Sorbonne, C.E.S.

pascal.assmutheuni-bielefeld.de

This work was carried out within International Research Training Group EBIM (Economic Behavior and Interaction Models) financed by the DFG under contract GRK 1134/2.

I would like to thank Herbert Dawid, Antoine Mandel and participants of the 20th 'Workshop on Economic Science of Heterogeneous Interacting Agents' for very useful comments and remarks. 


\section{Introduction}

Firms suffer from discrimination in access to credit (Canepa and Stoneman, 2008; Hao and Jaffe, 1993; Giudici and Pateari, 2000). This pattern of constraints can reinforce disturbances in the selection process. For example, those firms that are less profitable and less innovative are expected to grow at a comparatively low rate or to exit the market under an efficient mechanism in place. This is however, not observed in an Italian sample when there are financial constraints (Bottazzi et al., 2006, 2014; Bottazzi et al., 2010). Public subsidies can remedy constraints as they not only help most those firm in dire need of external funding (Hyytinen and Toivanen, 2003) but also increase the trust in creditworthiness by others and thus may enable external financing in the future (Takalo and Tanayama, 2010).

The aim of the paper is to explore which role the determinants of lender behaviour play in the evolution of a diversified economy. Therefore, we employ a rating process that determines the credit supply for each individual firm of two sectors. We examine the role of weights put on various pieces of information used for the rating like cash flow or market share. We also examine the impact of different ways of expectation formation about the prospects of the sectors.

We ask first what is the impact of the bank routines for credit supply on innovation and technology diffusion? The focus is on gaining insight about the dynamic of the bank decision in response to risk and furthermore in response to rather optimistic or conservative expectation formation.

In order to grasp insights we consider the following more detailed questions: to what extent does the bank policy determine whether one of the two sectors benefits? And which effect does the funding of the more innovative sector have on the low-tech sector?

We use a two-sector approach in order to bundle firms in an innovative and in an less innovative sector. We call the more innovative sector 'high-tech' and the less innovative one 'low-tech'. Banks that use internal rating/ scoring systems evaluate the creditworthiness of a firm in comparison to its rivals. Therefore, even if a firm does better than all firms in another sector, it might still be seen as an under-performing entity. The particular importance that the bank puts on sector-specific and economy-wide indicators in measuring creditworthiness may lead to different economic dynamics.

Innovation is subject to sufficient funding of the R\&D effort. However, firms are constrained in financing R\&D for several reasons. Explanations are based on the information shortage of external financiers compared to the firm. This disadvantage leads credit or equity providers to require a higher risk premium. Furthermore, even if $R \& D$ leads to some innovation that can be implemented, it does not yield tangible assets that can serve as col- 
lateral for a loan. This also contributes to the risk premium (Mohnen et al., 2008; Czarnitzki and Hottenrott, 2011). Furthermore, the outcome of R\&D projects is highly insecure and monitoring them is costly. Therefore, firms might not be able to be granted credit for R\&D to the amount they would like to (Freel, 2007). For a United Kingdom data-based empirical study, Freel (2007) finds that small firms that are innovative actually experience less credit granting success than their less innovative competitors. In a sample of US and UK small and medium-sized enterprises [SMEs] more innovative firms face a higher probability of not being financed externally although they are not more likely to apply for it (Mina et al., 2013). Supportive findings concerning high-tech firms are provided by Guiso (1998) who uses Italian samples where cross-sectional data shows that manufacturers in high-tech categories have a higher probability of being constrained in credit. The explanation refers to higher uncertainty related to producing at the edge of technology.

Furthermore, it is reported that the availability of external finance is more constrained for very innovative firms, more precisely, the relation between innovative ability and access to credit is inversely u-shaped (Czarnitzki and Kraft, 2004). This is supported by the evidence mentioned above that considers sub samples of firms that are more likely to be constrained, namely small and medium enterprises and young firms. Because those lack either collateral and/or a proven history of creditworthiness, their ability to pay back a loan is highly uncertain. The effects constraints have are less that projects are not carried out to the full extent but rather that they are not started at all (Mancusi and Vezzuli, 2010). Constraints in external funding affect R\&D efforts of firms in the first place (Brown et al., 2009; Mohnen et al., 2008). Aghion et al. $(2005,2012)$ find that credit rationing influences the R\&D policy of French firms where the effect depends on the degree to which firms are financed externally. Explanations range from fluctuations in R\&D spending that are due to lack of financial institutions (Hyytinen and Toivanen, 2003) to higher costs of external capital as identified in Dutch samples (Mohnen et al., 2008), Italian manufacturing samples (Mancusi and Vezzuli, 2010), French manufacturing firms (Savignac, 2007), and US vs. European samples (Ravera and Canet, 2001).

Ben-Zion (1984) mentions that research investment increases in economically favourable times and Yildizoglu (2002) points out that firms who do not experience success of R\&D after a while tend to abandon research activities. Also high competition among firms leads to lower R\&D. For firms, $50 \%$ of spending on R\&D is due to high wages for knowledge workers (Brown et al., 2012). Therefore, "[f]irms tend to smoothen R\&D investment over time in order to avoid having to lay off knowledge workers." (Hall and Lerner, 2009, p.5). Firms try to mitigate their dependence on outside funding by building up cash reserves which allow them to smoothen R\&D activity over time. Brown et al. (2009) find that an improved supply of equity can trigger an R\&D boom because relatively young firms benefit from that. Consequently, a lack of equity supply also can lead to a bust in R\&D activity as the R\&D 
cycle in the U.S. in the 1990s showed. Moreover, firms that have a high R\&D intensity suffer comparatively more from constraints because they usually require relatively higher external funding (Piga and Atzeni, 2007).

Bank credit is the major source of external financing (Hall and Lerner, 2009). Banks across the world need to provide a rating for their debtors according to the Basel II agreement. They can do ratings on their own (internal rating) or rely on external ratings provided by rating agencies (European Parliament, 2006). In fact, for granting credit to SMEs in Europe, banks use mostly internal rating systems (Centre for Strategy and Evaluation Services [CSES], 2014). There are many commonalities between internal and external ratings and external ratings are usually used for large companies above a particular threshold of market value. The crucial differences between pieces of information used for rating are whether they are of quantitative or qualitative nature. Quantitative information can be extracted from financial statements such as the balance sheet. Those pieces of information are backwardlooking. Although the probability of default (of repayment) is the crucial figure to estimate, banks do rely mostly on heuristic methods to assess that probability, even if there are also statistical and causal analytical methods, like models of option pricing. One reason is that statistical methods are only meaningful if the data set is sufficiently large (Reichling et al., 2007, p. 55). In order to assess the likelihood of credit repayment, a forward looking approach is necessary: "[a]ssessing an obligor's resources for fulfilling its financial commitments is primarily a forward-looking exercise."(Standard and Poor's, 2011, p. 5.) Moreover, "[a]n assessment that only includes the present must not be decisive - the [firm's] focus on the orientation to the future must be satisfactory." (Kremer and ten Hoevel, 1989, p. 122.) The prospect requirement is also an explicit demand of the European Union for internal rating methods to be approved: "[i]nformation shall be current and shall enable the credit institution to forecast the future performance of the exposure." (European Parliament, 2006, Annex VII, Part 4, Paragraph 18.) An important part in the assessment of creditworthiness is the evaluation of the market growth, because that represents the prospect of the particular industry the firm does business in (Reichling et al., 2007; Czarnitzki and Kraft, 2004). This can usually only be achieved by assessing the available information qualitatively. For evaluating European SMEs, the reportedly most important pieces of information are management quality, project quality or market sector (CSES, 2014). Usually, banks use $20-40 \%$ of qualitative information and the rest quantitative while for banks specialized in servicing SMEs the share of qualitative information may be in the range of $60-80 \%$ (CSES, 2014). There are however, differences in rating models in terms of which model is used for processing the information into a default probability. For an overview, refer to Crouhy et al. (2000) who report different approaches from four private companies or Reichling et al. (2007) who give an overview about the pieces of information used by banks and rating agencies. 
This paper contributes to explaining empirical findings about financial constraints and innovation by assessing the role of bank routines on financing constraints and heterogeneity found in constraints. By modeling bank routines in an evolutionary framework it provides one possible explanation of observed phenomena, for example that highly innovative firms being even more restricted. The model builds upon literature about risk management and $R \& D$ behaviour and on the theoretical approach of innovation embedded in an evolutionary context.

The model is set in a dynamic agent based framework building on the work of Nelson and Winter (1982) and Winter (1984) which is designed in an evolutionary environment under Schumpeterian competition. In each period the bank uses information about the firms in order to determine how much credit it would be willing to lend to each of them. It has a particular routine of doing so by relying on the assessment of creditworthiness based on multiple features. There are two sectors and each firm produces and conducts R\&D to some extent. The outcome is some quantity of a homogenous good in each sector which jointly with all other firms in the sector determines the market price. Also the profit of each firm is determined automatically on the one hand. On the other hand the R\&D effort might lead to the finding of a better technology which the successful firm can use in the production process of the next period. This leads the successful firm to wanting to invest more for the next round of production. However, this possibility depends on the current profit and available credit. If the firm can exploit that technological improvement it will have better access to credit in the next period.

There are two feedback effects employed in the model: a better technology improves access to credit and access to credit improves the probability of finding a better technology. Both effects are however, subject to individual behaviour of both, the bank and the firms. Thus, the effectiveness of the feedback varies in the behavioural routine of the agents. The bank uses information that applies in comparison to all other firms and it uses pieces of information that are sector-specific like market share. Furthermore, the bank needs to form expectations if it wants to assess the prospects of the respective industry.

Results indicate that the more the bank supplies credit based on information distinguished by sector the less innovation and output growth will take place. The reason is that innovative firms cannot benefit to the full extent from their superior productivity. That is, their success is recognized only with respect of their sector and not economy-wide and therefore they cannot gain as much from their advantage.

Furthermore, the way that the bank forms expectations about productivity only matters when all other pieces of information for the rating decision are taken into account in a rather marginal way. If they are of some importance it almost does not matter how the 
bank asserts the future productivity because the magnitude is too low. Predominantly, expectations are overshadowed by information about current cash flow and survival ratios in an industry. Nevertheless, the expectations have an impact on the shifting of credit between the sectors. The positive impact of higher average productivity growth however, does lead to a shift of funds to the other sector. The reason is that more trend-following expectations also exhibit more short-term variation as they follow the current and everchanging trend. This trend is more short-lived and works in both directions as occasionally high growth will hardly be sustained in the next period. If the expectations focus more on the long-term average occasionally high growth has a more persistent impact. Therefore, under conservative expectations, the bank shifts more funds to the more successful sector in the long run.

The remainder of the paper is organized as follows: section 2 introduces the model and section 3 establishes a baseline case. In section 4 the impact of the rating procedure on the sectoral evolution is examined. In section 5 we discuss the role of expectations on the bank's decision and the possible impact in this framework. Section 6 concludes.

\section{Setup}

Output $Q$ is generated by technology $A$ and capital $K$ by each firm $i$ at each period $t$ :

$$
Q_{i t}=A_{i t} K_{i t} \text {. }
$$

There are two sectors $I$ and $J$, where $I$ is considered to be a low-tech sector and $J$ is considered to be a high tech sector. Total output per sector is equivalent to demand in each sector

$$
\begin{aligned}
& D_{I} \equiv \sum Q_{i t} \forall i \in I \\
& D_{J} \equiv \sum Q_{i t} \forall i \in J .
\end{aligned}
$$

We assume that the goods are completely non-rival such that demand for each good is independent of the other sector. The inverse demand function determines the price

$$
\begin{gathered}
P_{I, t}=\frac{D_{I}}{\sum_{i} Q_{i t}}, \forall i \in I \\
P_{J, t}=\frac{D_{J}}{\sum_{i} Q_{i t}}, \forall i \in J .
\end{gathered}
$$


Capital is subject to depreciation at rate $\delta$ and investment $I$.

$$
K_{i(t+1)}=I\left(\frac{P_{t} A_{i(t+1)}}{c}, s_{i t}, \pi_{i t}, \delta\right) K_{i t}+(1-\delta) K_{i t}
$$

A firm's desired investment is determined by the ratio of price to production cost $\frac{P_{t} \cdot A_{i t+1}}{c}$ or, equivalently, the percentage margin over cost, the depreciation rate $\delta$ and its market share $s_{i t}$. A firm's ability to finance its investment is constrained by its profitability. Profitability $\pi_{i t}$ is determined by the productivity cost difference per unit of capital and the spending on last periods loan, which is determined by the interest rate $i$ and the loan per unit of capital $l_{i t-1}$ taken in the last period by the firm:

$$
\pi_{i t}=\left\{\begin{array}{l}
P_{I, t} A_{i t}-c-i_{i t-1} l_{i t-1}, \quad \forall i \in I \\
P_{J, t} A_{i t}-c-i_{i t-1} l_{i t-1}, \quad \forall i \in J .
\end{array}\right.
$$

Firms try to obtain better technology. They spend some amount $\Phi_{i t} K_{i t}$ on R\&D. The probabilities of finding (drawing) new technologies are determined by imitation and innovation respectively and depend positively on the firm size, i.e. the amount of capital, some positive factor $a^{i m}, a^{i n}$, and the usage of R\&D spendings $\Phi_{i t} K_{i t}$

$$
\begin{aligned}
& \operatorname{Prob}\left(d_{i m}=1\right)=1-e^{-a^{i m} K_{i t} \Phi_{i t} \kappa_{i t}} \\
& \operatorname{Prob}\left(d_{i n}=1\right)=1-e^{-a^{i n} K_{i t} \Phi_{i t}\left(1-\kappa_{i t}\right)}
\end{aligned}
$$

where $\kappa_{i t}$ is the share that determines the allocation of funds to imitation. ${ }^{1}$ Assume that a firm does either imitation search or innovation search only. This depends on whether it actually employs the best technology already or whether it uses less efficient technology. The rationale is that a technology leader has nothing to copy from and can thus devote all financial means of research to innovative search. ${ }^{2}$ Firms with less efficient technology would then strictly search any possibility to copy existing technology. This is a drastic statement but also very simple. A precondition is that there is common knowledge about the highest technology. ${ }^{3}$ Let $\hat{A}_{I t}, \hat{A}_{J t}$ be the best technology of the respective sector. The choice of

\footnotetext{
${ }^{1}$ These probabilities are inspired by Dosi et al. 2011.

${ }^{2}$ The particular role both, innovation and imitation play in economic growth is subject to a lot of discussion and research. While innovation breaks ground to better techniques, the diffusion of this techniques as firms reorganize usually leads to the real push in economic activity. See for example, Fagerberg and Verspagen (2002) for some discussion.

${ }^{3}$ Other models employ a more sophisticated and incremental choice between imitation and innovation effort which then does not require common knowledge. See, for instance, Colombo et al. (2012).
} 
R\&D investment policy also is depending on the sector such that

$$
\kappa_{i t}=\left\{\begin{array}{l}
0, \text { if } \hat{A}_{I, t}=A_{i t}, \forall i \in I \\
0, \text { if } \hat{A}_{J, t}=A_{i t}, \forall i \in J \\
1, \text { else. }
\end{array}\right.
$$

Each firm may conduct some $R \& D$ in a period. This is a two stage process where it first may or may not draw an innovation or imitation. In case of drawing an imitation the firm adopts the industry's best technology. Successful draws are indicated by

$$
\chi_{i t}^{i m, i n}=\left\{\begin{array}{l}
1, \text { if there is a successful draw of imitation (im) or innovation (in), } \\
0, \text { else. }
\end{array}\right.
$$

If the firm draws an innovation, it gets a sample from a distribution of technical opportunities determined by $F\left(\tilde{A}_{i t} ; A_{i t}\right)$ where $\tilde{A}_{i t} \sim \operatorname{LogNormal}\left(A_{i t}, 1\right)$. This implies that any innovation that is found is actually better than the currently employed technology. The technology that a firm can use in the next period is the best technology available to that firm. That is, it is the best technology among the current individual technology, the best technology in the sector if an imitation was drawn or the innovation that was drawn

$$
A_{i(t+1)}=\left\{\begin{array}{l}
\operatorname{Max}\left(A_{i t}, \hat{A}_{I, t} \chi_{i t}^{i m}, \tilde{A}_{i t} \chi_{i t}^{i n}\right), \forall i \in I \\
\operatorname{Max}\left(A_{i t}, \hat{A}_{J, t} \chi_{i t}^{i m}, \tilde{A}_{i t} \chi_{i t}^{i n}\right), \forall i \in J
\end{array}\right.
$$

Given the anticipated technology of the upcoming production round a firm demands capital investment according to the functions

$$
\begin{aligned}
I_{i t}^{d} & =1+\delta-\frac{\mu_{i t}}{\frac{P_{t} A_{i(t+1)}}{c}} \\
\mu_{i t} & =\frac{\varphi-(\varphi-1) s_{i t}}{\varphi-\varphi s_{i t}}
\end{aligned}
$$

where $\mu_{i t}$ is the markup power a firm could exert. This markup consists of some positive parameter $\varphi$ and the current market share of a firm $s_{i t}$. The higher the market share, the higher is the markup (Winter, 1984, p. 319). The investment demand then depends negatively on the markup and positively on the price-over-cost margin of the firm. Firms determine their R\&D effort according to prior success of research and in boom times the firms tend to increase R\&D. Denoting $\Phi_{i t}$ the per unit of capital R\&D spending of a firm $i$ at $t$, the firm changes R\&D spending according to the factor $\Omega_{i t}$. Desired spending on R\&D 


$$
\Phi_{i t}^{d}=\operatorname{Max}\left[\Phi_{i t-1}\left(1+\Omega_{i t}\right), b^{R D}\right]
$$

with

$$
\Omega_{i t}=\lambda^{F}\left(\pi_{i t-1}-\pi_{i t-T-1}\right)
$$

where $T$ is the number of past periods taken into account and $\Omega_{i t}$ determines the change in $R \& D$ demand. Assuming that firms adapt their target R\&D spending by reacting positively on profit changes, $\lambda^{F}>0$ is a parameter of the adjustment speed. Furthermore, $b^{R D}>0$ represents a basic $R \& D$ target which the firm always wants to conduct. This behavioural rule is intended to capture increases in R\&D spending in economically favourable times (BenZion, 1984) and the reducing of R\&D activity if the firm's success decreases or if competition is too tight which reduces profitability (Yildizoglu, 2002). Note that there will be always a non-zero level of desired R\&D This feature does not completely match with the statement of Yildizoglu (2002) which indicates that firms without R\&D success will abandon research completely. Note also that, compared to the Nelson-Winter approach it is just profit and savings that determine investment possibilities.

Together with R\&D demand $\Phi_{i t}^{d}$ the firm has demand for expenditures $E_{i t}^{d}=\Phi_{i t}^{d}+I_{i t}^{d}$. Denote $C_{i t}=\pi_{i t}+S_{i t-1} / K_{i t}-l_{i t-1}$ as liquidity per unit of capital. It consists of profitability and accumulated savings minus the last periods credit that has to be repaid. By assuming a strict hierarchy in financing, a firm would first use profit to finance investment and then refer to its savings. If investment demand exceeds liquidity there is demand for additional cash in the form of credit. Credit demand is the difference needed for financing

$$
l_{i t}^{d}=\left\{\begin{array}{l}
E_{i t}^{d}-C_{i t} \text { for } C_{i t}<E_{i t}^{d} \\
0 \text { else }
\end{array}\right.
$$

The average credit supply per unit of capital $l^{s}$ is assumed to be constant. Total credit supply in absolute terms is $l_{t}^{s}=l^{s} \cdot \sum_{i} K_{i t}$. Given its capital share in the economy the per unit of capital credit supply for any firm is ex ante $\frac{l_{t}^{s}}{K_{i t}}$.

The bank supplies credit by distinguishing the two sectors via setting the weight factor $\lambda_{t}^{s}$. This applies via $\omega_{i t}$

$$
\omega_{i t}=\left\{\begin{array}{l}
\lambda_{t}^{s}, \text { for } i \in I \\
\left(1-\lambda_{t}^{s}\right), \text { for } i \in J
\end{array}\right.
$$

The bank supplies credit to individual firms by ranking them according to their profitability 
and their market share. This represents the rating process in this model. The relative importance of profitability and market share is determined by setting $\lambda \in[0,1]$. The credit supply rule that the bank applies is

$$
l_{i t}^{s}=\left\{\begin{array}{l}
\frac{l_{t}^{s}}{K_{i t}}\left(\lambda \frac{\pi_{i t-1}}{\sum \pi_{i t-1}^{\text {pos }}}+\omega_{i t}(1-\lambda) \frac{Q_{i t-1}}{\sum\left(Q_{i t-1}\right)}\right), \text { for } \pi_{i t-1}>0 \\
\frac{l_{t}^{s}}{K_{i t}}\left(\omega_{i t}(1-\lambda) \frac{Q_{i t-1}}{\sum\left(Q_{i t-1}\right)}\right), \text { else. }
\end{array}\right.
$$

This applies to both sectors, where $\sum \pi_{t-1}^{p o s}$ is the sum of all profits from firms that yielded positive profits. Therefore, firms with positive profitability get credit supplied according to their relative position in the set of all profitable firms. This specification hence avoids some potential problems for the case that -due to negative profits- some firms' profits are huge relative to the average profit. Thus, the bank takes into account relative profitability and relative technology level. This also means that total credit supply, $l_{t}^{s}$, is not necessarily used completely as firms with negative profit are only offered a share computed by $(1-\lambda)$ times the market share.

The parameter $\lambda_{t}^{s}$ shows the weight the bank puts on each sector. This weight may be adaptive and depend on the expected return, possibly through the survival and thus repayment rate, from each sector. If the sectors are different, then the expected return can be very different. The allocation choice should be such that $\lambda_{t}^{s} \in[0,1]$. Determine $f_{t}$ as the deficit rate in a sector which expresses a proxy for non-recoverable credit

$$
f_{t}=\frac{\# \text { Exits }_{t}}{\# \text { Firms }}
$$

and the average over $H$ periods

$$
\bar{f}_{t}=\frac{1}{H} \sum_{h=0}^{H-1} f_{t-h}
$$

in the respective industry. Choosing $a_{\lambda} \in[0,1]$ as an adaptation speed parameter, the bank's choice is made according to

$$
\lambda_{t}^{s}=\operatorname{Min}\left[1, \operatorname{Max}\left[0, \lambda_{t-1}^{s}+a_{\lambda}\left(\bar{f}_{J, t-1}-\bar{f}_{I, t-1}\right)\right]\right]
$$

If for example, the default rate in industry $I$ is higher than in industry $J$, the last term is negative and the bank shifts more credit to sector $J$ by reducing $\lambda^{s}$. This rule is inspired by actual bank rating practice as reported by Reichling et al. (2007). They state that banks classify firms in categories and then assess the risk of credit default by looking at past default ratios of firms having been in the respective category. Since in this model, risk is accounted for by rationing credit, less credit is supplied to the sector that is perceived to be riskier by 
the bank. The bank proxies this risk by the drop-out rate in the industry.

Some sectors of the economy are regarded to be R\&D-intensive, like pharmaceuticals or the aerospace industry (Deutsches Institut für Wirtschaftsforschung [DIW], 2009). Therefore, we assume that the so-called high-tech sector $J$ in our model is aiming at conducting a basic level of R\&D that exceeds the one of the so-called low-tech industry $b_{J}^{R D}>b_{I}^{R D}$. We also assume that the high-tech sector has a better chance of drawing an innovation/ imitation given the same spending on R\&D such that $a_{J}^{i m, i n}>a_{I}^{i m, i n}{ }^{4}$ Credit is allocated among the firms applying for it. Then,

$$
l_{i t}=\operatorname{Min}\left[l_{i t}^{d}, l_{i t}^{s}\right]
$$

The investment constraint is

$$
I_{i t}^{c}=C_{i t}+l_{i t}
$$

Actual capital investment is then determined by this constraint and the desired capital investment. Actual R\&D spending is furthermore determined by the amount of liquidity not used for physical investment and the R\&D desire

$$
\begin{aligned}
I_{i t} & =\operatorname{Min}\left[I_{i t}^{c}, I_{i t}^{d}\right] \\
\Phi_{i t} & =\operatorname{Min}\left[I_{i t}^{c}-I_{i t}, \Phi_{i t}^{d}\right] .
\end{aligned}
$$

The firms save money not invested. Savings evolve according to:

$$
S_{i t}=S_{i t-1}+\left(\pi_{i t}+l_{i t}-I_{i t}-\Phi_{i t}\right) K_{i t}
$$

as in Colombo et al., (2012). Note that savings are noted as absolute numbers and cannot be negative.

Entry takes place according to a two-stage process. First, there is exogenous activity and thus the number of potential imitators and innovators is determined. Then, those draw a random technology. A constant for innovation $N=0.05$ and imitation $M=0.05$ determines the number of potential entrants for innovation and imitative behavior in each of the two sectors. After drawing an individual technology, entry takes place if the potential entrant in a sector has drawn at least the currently average technology in the sector. The other features of the entrants like capital are then further determined randomly under a uniformly distributed probability within the range of existing firms' features. Assume that entrants also apply the strategy $\Phi^{\text {ini }}$ as well.

\footnotetext{
${ }^{4}$ See Marsili and Verspagen (2002) on differences between 'technological regimes'.
} 
The driving force of the model is the difference in technology. It determines the relative profitability in each sector. According to an adjustment in firm sizes and therefore output there is a decrease in the market price. This puts pressure on all other firms in the industry and provokes selection.

If there is enough funding available, either due to retained profits or credit, a given change in a firm's technology triggers more pressure on the competitors if this is a very big firm. Since output increases relatively more in this case the price is driven down significantly. There are two channels at work in the dynamics of the model: firm size via investment and technology via R\&D. Both determine a single firms' output and thus the overall price level in the industry (indirect feedback).

The main mechanism in the Nelson-Winter model would lead to a steady state market which means that the behavioural rule of investment demand has a converging effect. This is due to the influence of the market share: the higher the market share, the less investment is desired. Furthermore, a better technology always increases investment demand because it always improves the price-over-cost margin, except in the monopoly case where it has no effect. Nevertheless, the availability of credit determines how severe the positive impact will be. This is an important feature of this model and in line with the findings of Lee and Harrison (2001) who claim that the benefits from R\&D and even innovation often are effective after some time lag and which then influence further R\&D behaviour.

\section{Baseline Case}

For the baseline case the bank will only regard market specific features $(\lambda=0)$. We will first examine a situation where there is no $R \& D$ conducted whatsoever $\left(\Phi^{d}=0\right)$. Recall the credit supply rule

$$
l_{i t}^{s}=\left\{\begin{array}{l}
\frac{l_{t}^{s}}{K_{i t}}\left(\lambda \frac{\pi_{i t-1}}{\sum \pi_{i t-1}^{p o s}}+\omega_{i t}(1-\lambda) \frac{Q_{i t-1}}{\sum\left(Q_{i t-1}\right)}\right), \text { for } \pi_{i t-1}>0 \\
\frac{l_{t}^{s}}{K_{i t}}\left(\omega_{i t}(1-\lambda) \frac{Q_{i t-1}}{\sum\left(Q_{i t-1}\right)}\right), \text { else. }
\end{array}\right.
$$

Note that according to the European Union's requirements for rating methods to be approved, the condition $\lambda>0$ is sustaining in practice since "consistency shall exist across lines of business, departments and geographic locations" (European Union, 2006, Annex VII, Part 4, Paragraph 17.(a) ) which means that comparability of all firms requires also information that is not market specific. The other parameters in this setting are credit supply $l^{s}=0.05$ and reaction intensity on default rate $a_{\lambda}=0.5$. For $\lambda_{i n i}^{s} \in[0,1]$ we examine the long run evolution of the economy. Then, we will introduce R\&D. Since there is no technological improvement in the baseline case we will only observe allocation effects as total output is relatively constant. Furthermore, as the two sectors only differ in their R\&D effort and 
success probabilities, in this baseline case they are the same. We look at economic features after some time period contingent of $\lambda_{i n i}^{s}$. We take results of periods $t \in[980,1000]$ where the model has evolved enough in order to distinguish for different long-term influences. We compute the average of that time span. We repeat this 100 times and take the average of those repetitions. This is done for each of ten different levels of $\lambda_{i n i}^{s}$. Results are depicted in figure 1.

\subsection{Baseline Case Without R\&D}

In the baseline case it is observable that the sector that gets credit supplied in the beginning will be supplied still in the long run (figure 1a). Furthermore, the supplied sector will have some investment and low concentration. This is indicated by output (figure 1c) and the Herfindahl-Index (figure 1d). Also, the number of firms is higher in that sector (figure 1e). Without improving technology the increased number of exits due to under supply of credit takes away capital and output. This is not offset by higher average productivity. Therefore, the initially supplied sector is less concentrated and its output is higher.

The use of credit also increases in initial credit supply (figures $1 \mathrm{~g}$ and $1 \mathrm{~h}$ ). However, due to exiting firms and lower output the prices are higher for the remaining firms which leaves those better off. They have a higher profitability and thus require less credit for financing (figure 1f). This is indicated by total profits (figure 1b). In the simulation the low tech sector makes negative total profits for higher $\lambda_{i n i}^{s}$. That means that it is likely that initially supplied firms are Ponzi-financed and need to pay a lot of interest for credit which cuts into profits. This is indicated by figure $1 \mathrm{~h}$. Firms in the low tech sector need furthermore an increasing amount of credit just to pay back old credit so that credit supply induces the need for further credit if there are no productivity gains.

Figures 2 and 3 show the dynamics over time of the economy for different initial allocation parameters. If the initial supply of credit is higher the credit supply for this sector is comparatively higher and lower in the other sector. In both cases of initial credit supply, the supplied sector evolves the same. A comparison of figures $2 a$ and $3 a$ shows that the economy evolves the same in both cases and the sectors are just interchangeable. Therefore, the supplied sector output is comparatively higher and at the same time, the market price is lower. This has implications for the profitability in the sectors. The supplied sector has a comparatively lower profitability since there are no technological improvements. This means that at the same time its share of external funds in financing investment is high (figures $2 \mathrm{~d}$ and $2 \mathrm{e}$ as well as figures $3 \mathrm{~d}$ and $3 \mathrm{e}$ ) but investment itself is at a high level as well. Therefore, there is a larger number of firms able to stay in the industry which drives down concentration (see figures $2 \mathrm{~b}$ and $3 \mathrm{~b}$ or figures $2 \mathrm{c}$ and $3 \mathrm{c}$ ). Heterogeneity among firm sizes occurs due to 


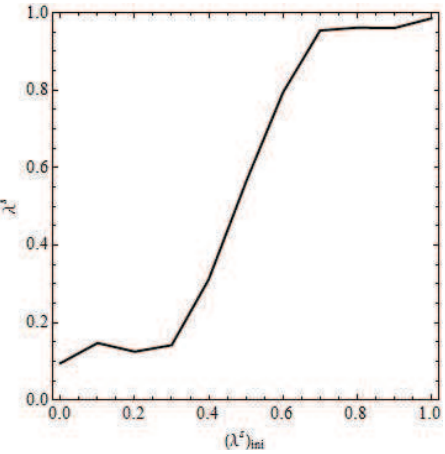

(a) allocation of credit

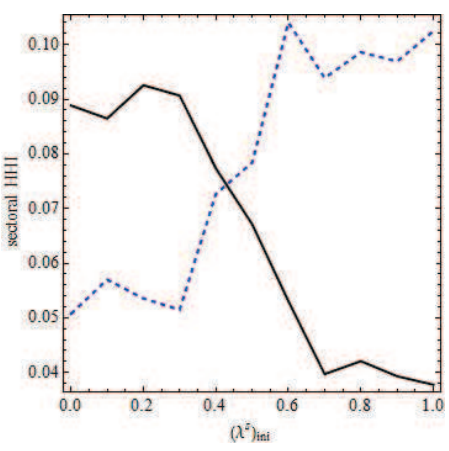

(d) Herfindahl Index

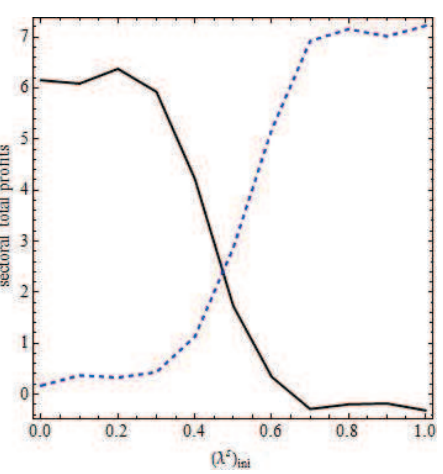

(b) total profit

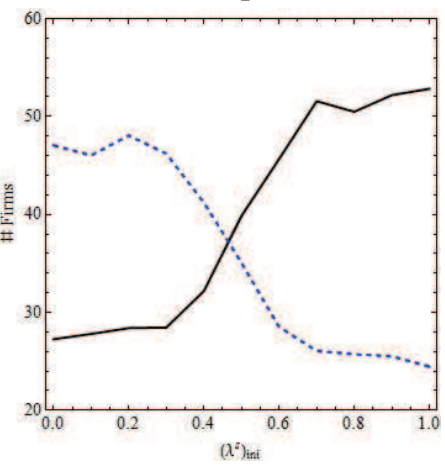

(e) no. of firms

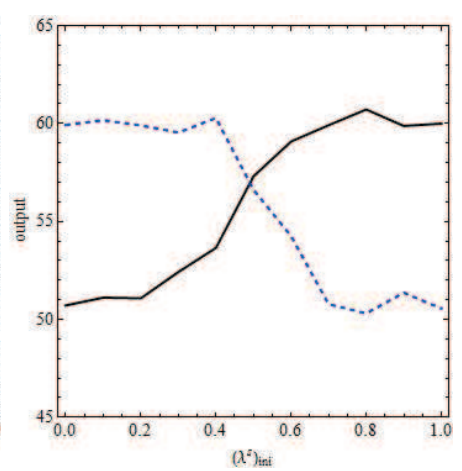

(c) output

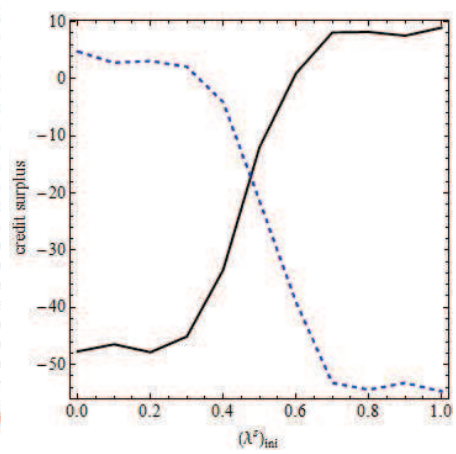

(f) credit surplus
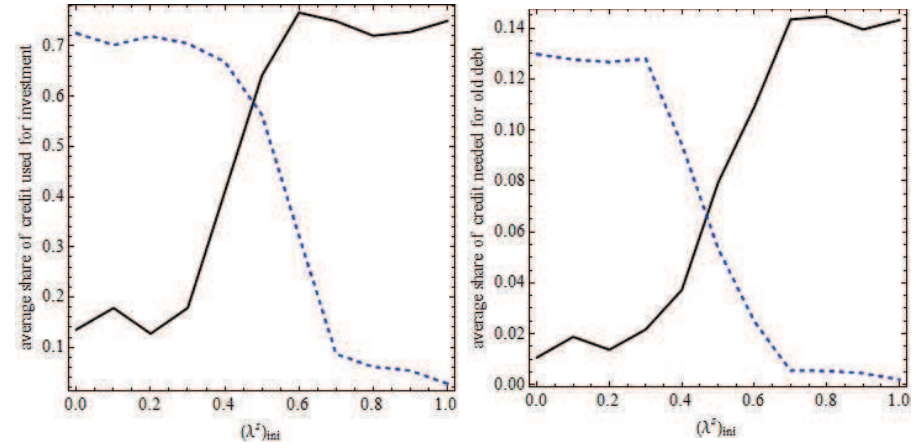

(g) share of credit demanded in (h) share of credit demanded in financing investment serving old debt

Figure 1: Impact of initial credit allocation - baseline case

(Black $\rightarrow$ Low Tech; Blue, Dashed $\rightarrow$ High Tech) 


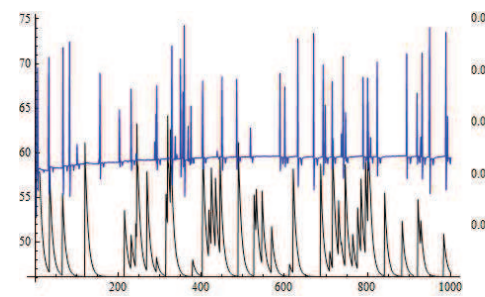

(a) output

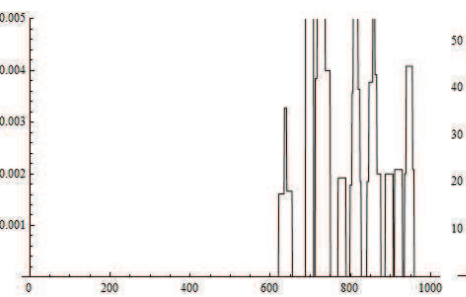

(b) bankruptcy rates

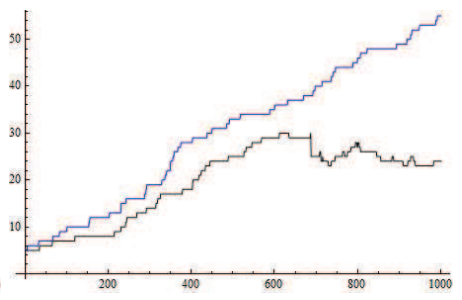

(c) number of firms

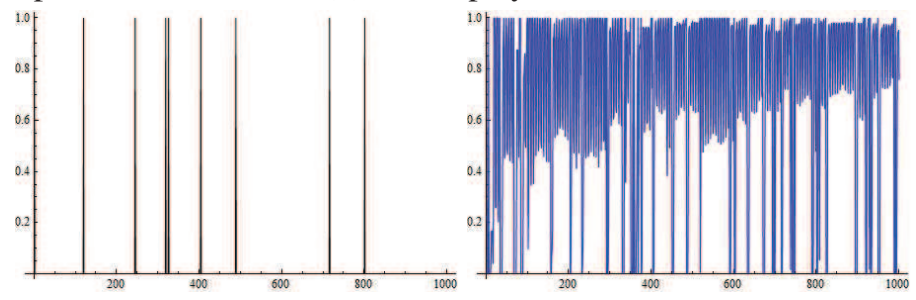

(d) share of credit needed for in- (e) share of credit needed for investment low tech vestment high tech

Figure 2: Over time dynamics for baseline case without $\mathbf{R} \& \mathbf{D}$ and $\lambda_{\text {ini }}^{s}=0$

(Blue $\rightarrow$ high-tech sector)

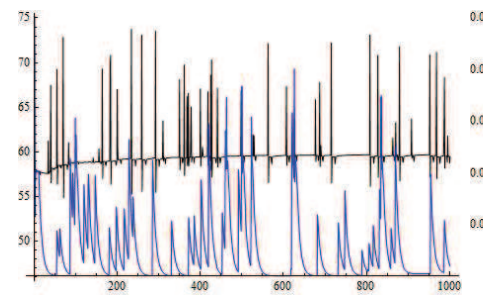

(a) output

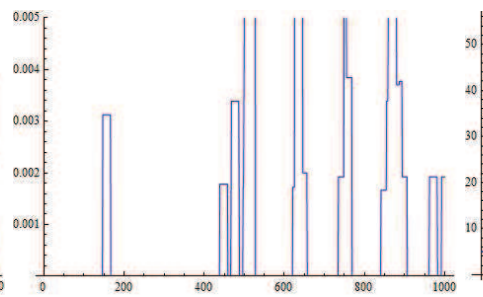

(b) bankruptcy rates

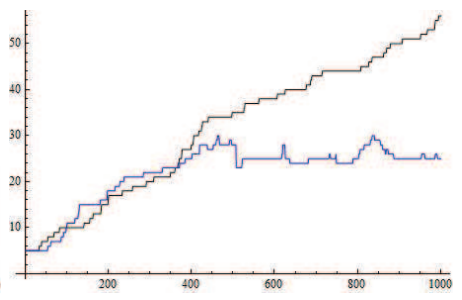

(c) number of firms

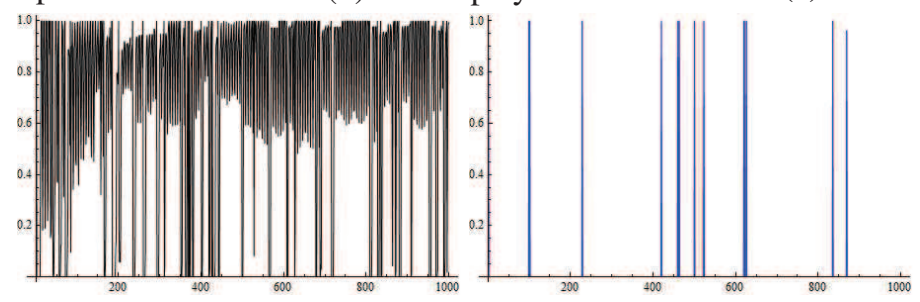

(d) share of credit needed for in- (e) share of credit needed for investment low tech vestment high tech

Figure 3: Over time dynamics for baseline case without $\mathbf{R} \& \mathbf{D}$ and $\lambda_{i n i}^{s}=1$

(Blue $\rightarrow$ high-tech sector) 
random entry with heterogeneous firm sizes. Only the market share matters for the relative supply of credit within the sector. Large firms therefore can drive small firms out of the industry just because of their collateral. For the well supplied sector this is not a problem since also the small firms have enough access to credit. The under supplied sector shows high concentration because credit is scarce. Nevertheless, total profits are low in the supplied sector because firms have to pay large amounts of interest for their funding which hurts profitability. Therefore, credit supply sustains the number of firms in the sector but not its profits.

\subsection{Baseline Case With R\&D}

We now ask whether the initial credit allocation has a similar impact if R\&D matters $\left(\Phi^{d}>0\right)$.

Figure 4 shows the impact of the initial allocation parameter $\lambda_{i n i}^{s}$ when the high tech sector is willing to conduct more basic R\&D, $b_{J}^{R D}>b_{I}^{R D}$ and has a higher probability per unit invested than the low tech sector as well $\left(a_{J}^{i m, i n}>a_{I}^{i m, i n}\right)$. The high-tech sector with a high R\&D intensity is much better off when it gets supplied credit in the first place. The output of the low-tech sector changes only marginally but the output of the high-tech sector decreases significantly in the initial allocation of credit (figure 4a). The lack of credit also hurts profits more in the high tech sector than its supply benefits the low-tech sector (figure 4b). Figure 4c indicates that a lack of credit is followed by a higher number of firms exiting the industry. This has implications for the long-term allocation of credit. Since the high-tech sector can grow because it has an initial high supply of credit, increased price pressure drives firms out of the industry. This raises bankruptcy rates and the bank shifts away credit to the low-tech sector (figure $4 \mathrm{~d}$ ). The number of innovations and imitations supports this view (figures $4 \mathrm{e}$ and $4 \mathrm{f}$ ). The lower sectoral profits for the high tech sector require that a higher share of investment needs to be financed by credit as figure $4 \mathrm{~g}$ confirms. Also, figure $4 \mathrm{i}$ indicates that initial allocation of credit does not matter for credit usage if firms can improve by conducting R\&D. The share of credit needed to set off old debt is low and does not vary in the initial allocation. There is only the exception when all credit is initially allocated to the high-tech sector. Because the high-tech sector starts with using a lot of credit and only diminished that usage over time when some firms improve upon technology sometimes the ratio may be high after 1000 periods. Compare figures $5 \mathrm{~d}$ and $6 \mathrm{~d}$ as well.

Figure 5 shows the dynamics over time for the baseline case with R\&D and initial allocation parameter $\lambda^{s}=0$ where the R\&D intensive sector is supplied all the credit. The images are averages taken from 10 runs. This supplied sector is able to innovate and hence increase output (figure $5 \mathrm{a}$ ) and the allocation parameter shifts to the low-tech sector over time (figure $5 b)$. The reason is that the high-tech sector is exposed to many exiting firms. The shift of 


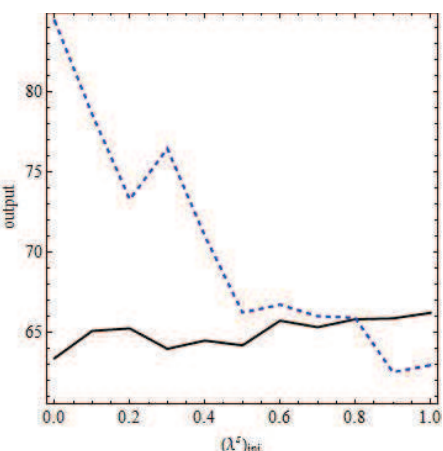

(a) output

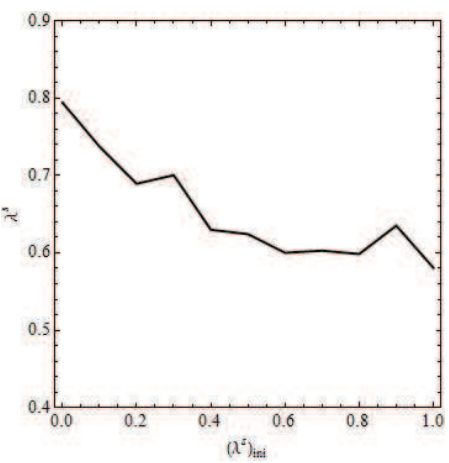

(d) allocation of credit

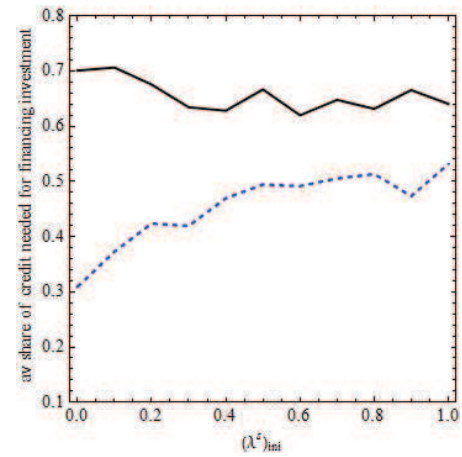

(g) share of credit needed for fi- (h) nancing investment

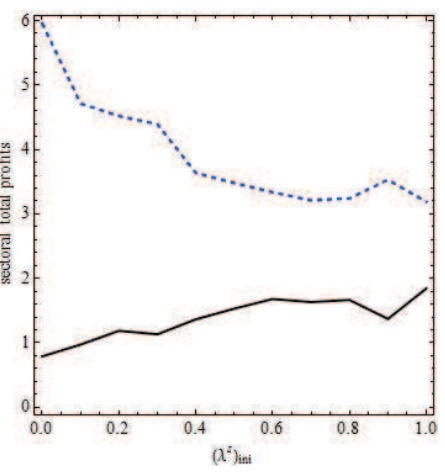

(b) total profit

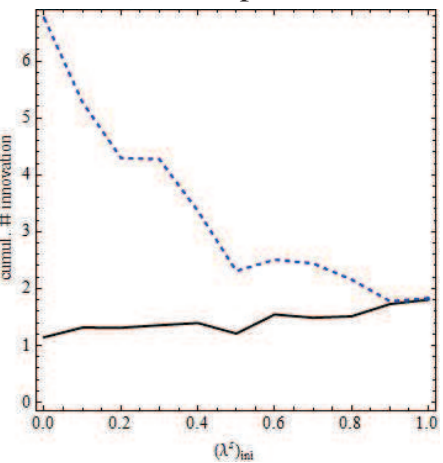

(e) no. of innovations

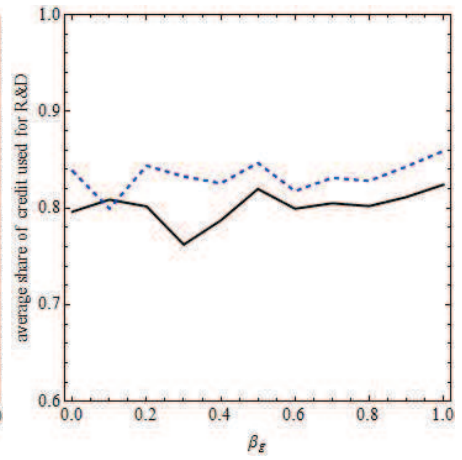

(h) share of credit needed for fi- (i) share of credit needed for nancing $R \& D$

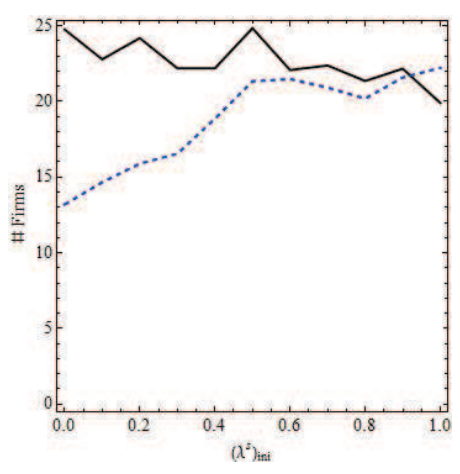

(c) no. of firms

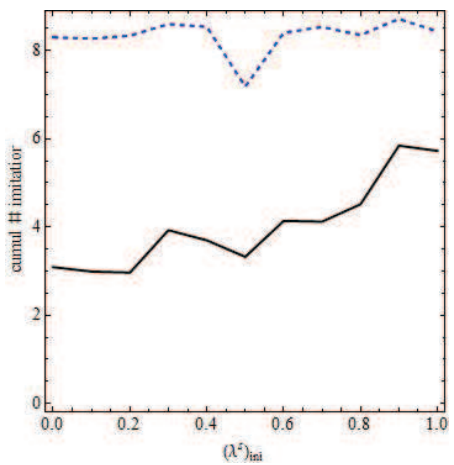

(f) no. of imitations

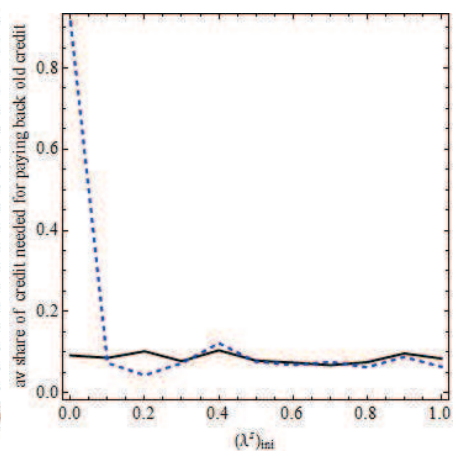

Figure 4: Impact of initial credit allocation with $R \& D$

(Black $\rightarrow$ Low Tech; Blue, Dashed $\rightarrow$ High Tech) 


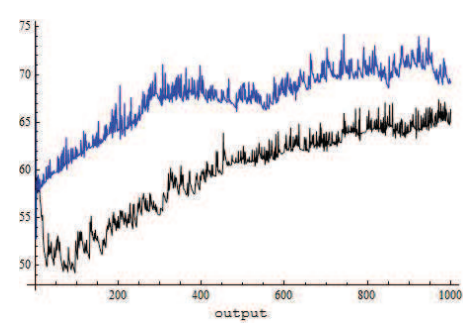

(a) output

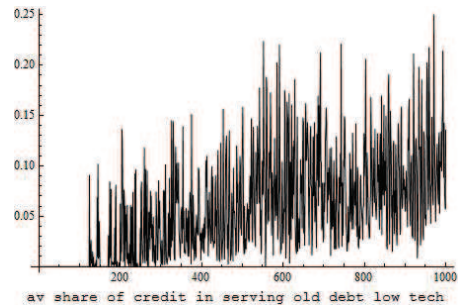

(c) share of credit needed for (d) serving old debt low tech

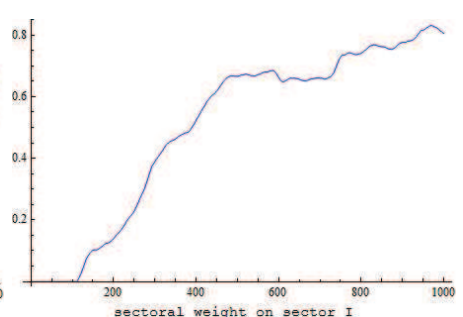

(b) $\lambda^{s}$

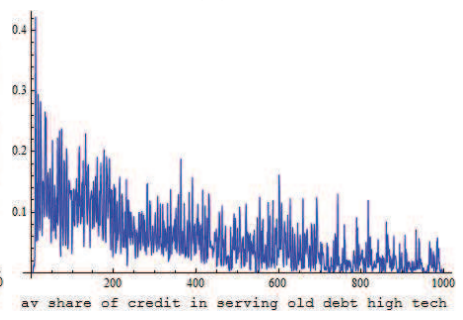

(d) share of credit needed for serving old debt high tech

Figure 5: Over time dynamics for baseline case with R\&D and $\lambda_{i n i}^{s}=0$

(Blue $\rightarrow$ high-tech sector)

credit to the low tech sector is clearly visible in the amount that firms need to refinance old debt (figures $5 \mathrm{c}$ and $5 \mathrm{~d}$ ). The low tech sector lacks credit supply but at the same time does not need to repay any loans which would cut into profits. After a while, this changes due to the allocation parameter of the bank and the low-tech sector needs to take a loan just to repay old debt. The same is observed in the opposite direction for the high tech sector. It initially has access to credit which leaves it in need of further credit for repayment. As there is no further credit supplied, this liability vanishes as well.

Figure 6 shows why an initial high supply of credit for the low tech sector leaves the sector being supplied even after a period of low supply. The periods when firms rely on credit to repay old debt do match with the allocation parameter again (compare figures $6 c$ and $6 \mathrm{~d}$ with $6 \mathrm{~b})$. The initial advantage of credit supply is more beneficial for the low tech sector which is able to evolve more quickly compared to the high-tech sector (figure 6a). This evolution also causes the credit to shift between sectors more quickly than in the opposite scenario. Nevertheless, the initial advantage of full supply lets the high tech sector evolve fast enough to be less reliant on credit. Figure $6 \mathrm{~d}$ compared to figure $5 \mathrm{c}$ indicates decreasing need to refinance old credit which confirms that view. 


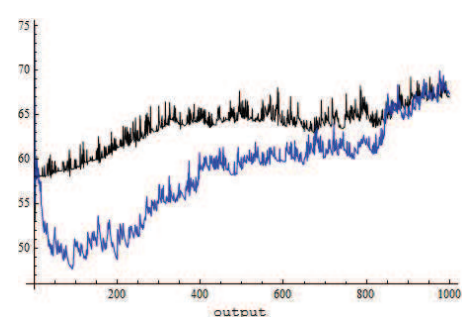

(a) output

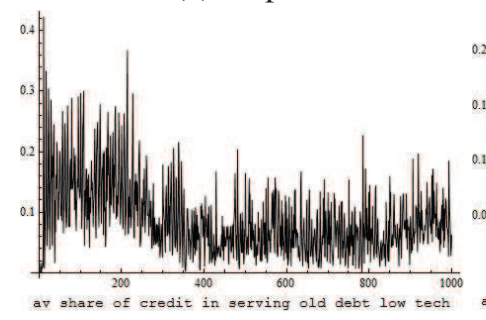

(c) share of credit needed for (d) serving old debt low tech

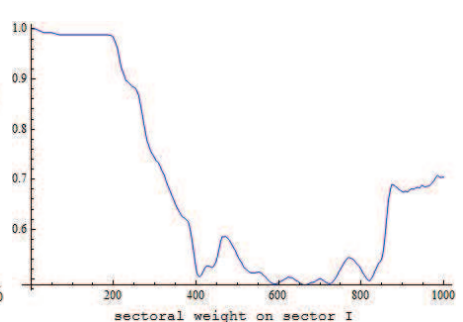

(b) $\lambda^{s}$

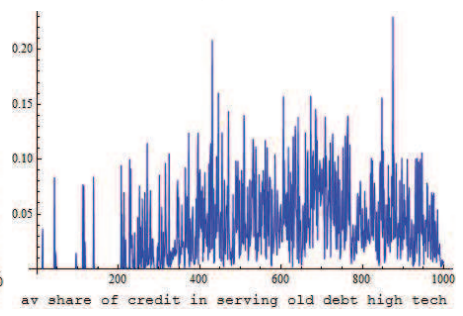

(d) share of credit needed for serving old debt high tech

Figure 6: Over time dynamics for baseline case with $\mathbf{R} \& D$ and $\lambda_{i n i}^{s}=1$

(Blue $\rightarrow$ high-tech sector)

\section{Bank Policy}

The bank can affect the dynamics of the industries by the weight $\lambda$ it puts on profitability. Recall that the bank policy is inspired by risk management literature where lenders estimate the creditworthiness of their borrower. They are giving it a rating classification number and then base their decision on it. The effect of this policy is that the sector that is more innovative will get relatively more credit for the better profitability of its member firms on the one hand, but will suffer from less credit supply due to the higher drop out rate that stems from increased competition in that sector.

Figure 7 depicts the results for an experiment of the impact of the weight on information in the rating process fixed by the bank. The results indicated are for incremental values of that weight $\lambda \in[0,1]$. The figure shows that the high tech sector prospers most in a situation where sector specific features do not matter $(\lambda=1)$. If the bank puts nevertheless, much weight on sector specific information $(\lambda=0)$ the evolution of both industries is slower with the exception that the low-tech sector has higher total profits (figure $7 \mathrm{c}$ ).

Output is affected much more for the high tech sector (figure 7a) than for the low-tech sector, where it is almost constant. As the industry concentration increases in both industries (figure $7 b$ ), it seems that it is mostly the exit of firms that leads to lower total profits in the low tech sector. Although the number of exits is much higher in the high tech sector (figure 7d) total profits increase. Also, credit surplus increases for both sectors (figure $7 \mathrm{f}$ ). This is due to the much higher number of innovations and imitation in the high tech sector (figures $7 \mathrm{~g}$ 


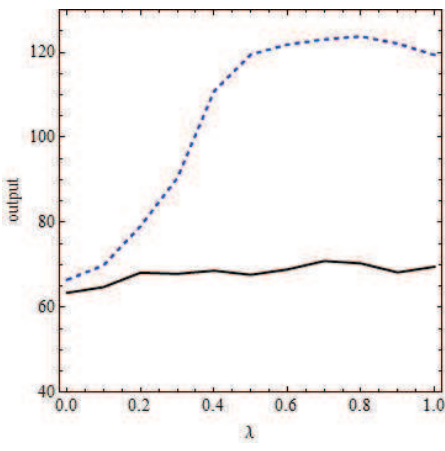

(a) output

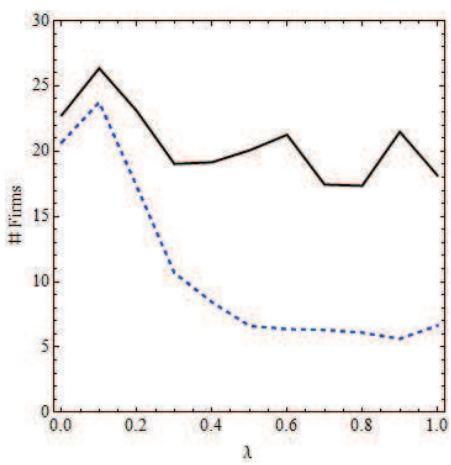

(d) no. of firms

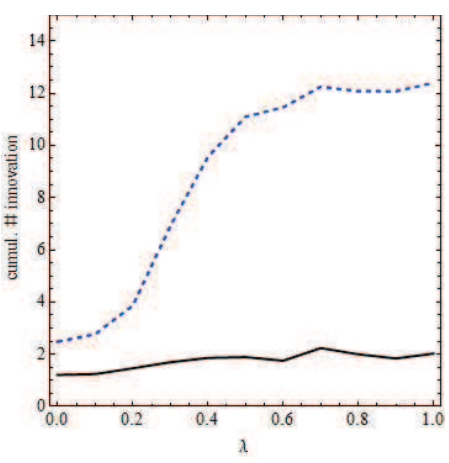

(g) cumul innovations

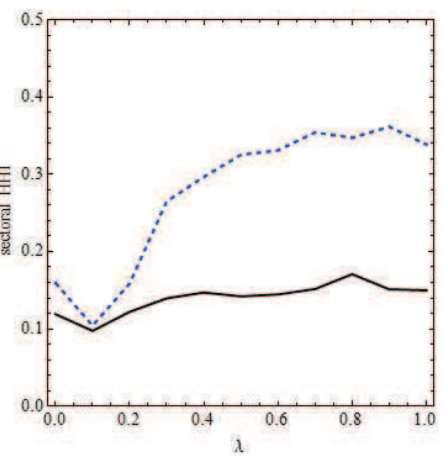

(b) $\mathrm{HHI}$

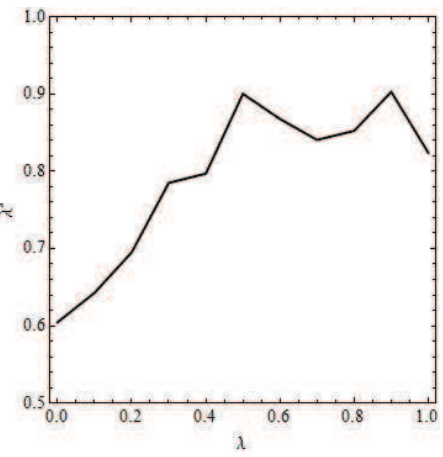

(e) $\lambda^{s}$

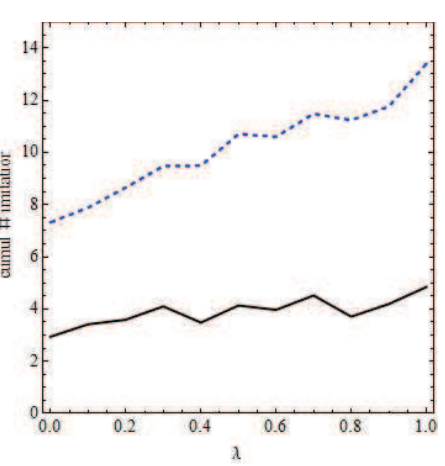

(h) cumul imitations

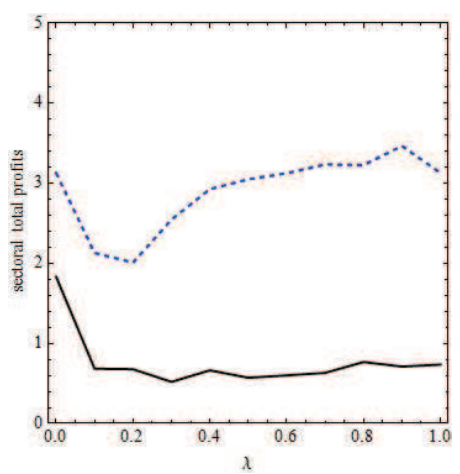

(c) total profit

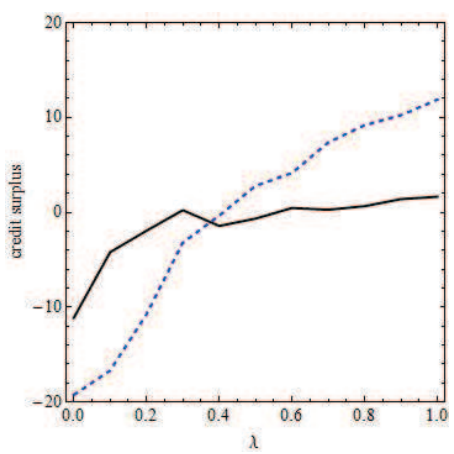

(f) credit surplus

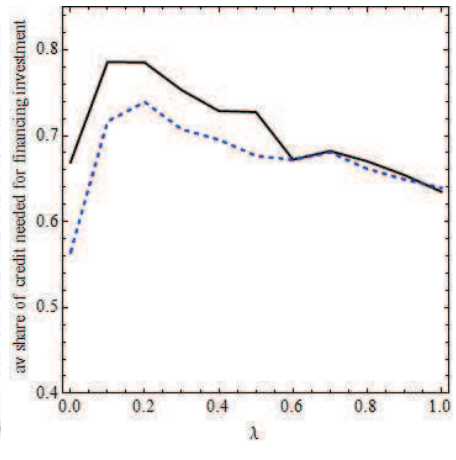

(i) share of credit needed for investment
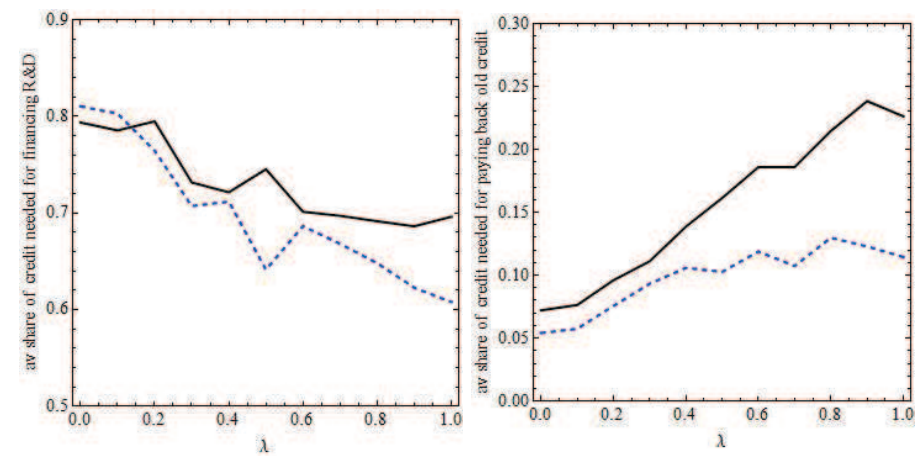

(j) share of credit needed for $(k)$ share of credit needed for $R \& D$ paying off old debt

Figure 7: Impact of rating weights in the two sector setup

(Black $\rightarrow$ Low Tech; Blue, Dashed $\rightarrow$ High Tech) 
and $7 \mathrm{~h}$ ). The bank allocates more credit to the low-tech sector (figure $7 \mathrm{e}$ ) which reduces negative credit surplus due to the increased supply. The high-tech sector makes more profits and due to less credit demand its credit surplus increases.

Furthermore, the technology gap between sectors widens and the weight put on the less innovative sector increases in $\lambda$. This is indicated by the number of innovations and imitations in figures figures $7 \mathrm{~g}$ and $7 \mathrm{~h}$. This happens although the bank allocates more credit to the low-tech sector. This allocation of credit induces a higher use of credit and a higher further dependence on credit (figures $7 \mathrm{i}$ through $7 \mathrm{k}$ ). Thus, the bank policy does have a distinct influence on the evolution of the economy: as it puts more weight on global competition, that is the profitability, it promotes the firms with the best cash flow and does not take into account credit defaults by exiting firms. It has to be pointed out however, that the credit supply is constant in units of capital, that is, as firms do leave the economy, credit supply in absolute terms is lower in the next period. As firms with better cash flow are promoted, there is more credit surplus as those firms do not require external funding. At the same time, the firms relying on external funding are offered comparatively less. There are more bankruptcies and a higher tendency toward monopolistic sectors. Furthermore, as $\lambda$ increases, the impact of $\lambda^{s}$ and $a_{\lambda}$, the default quota adjustment speed becomes more negligible. Innovation becomes more crucial since it has only a global effect. The disadvantage of innovation for a single sector due to increased competition, increased bankruptcies, vanishes for $\lambda=1$.

The parameter $\lambda_{t}^{s}$ is without meaning in this scenario. Figure 8 depicts the over time dynamics for $\lambda=0$ and figure 9 shows the dynamics if $\lambda=1$ for an average of 10 runs. If only market share matters $(\lambda=0)$ firms stay rather identical in each of the sectors. Furthermore, they are supplied with the same amount of credit since they all have the same market share. Both effects reinforce each other. Both sectors can grow almost equally with slight advantages for the high tech sector (figure 8a). The allocation parameter $\lambda_{t}^{s}$ increases a bit (figure $8 \mathrm{~d}$ ) which is the reason that the low tech sector has access to credit and is able to grow at about the same pace as the high tech sector. Figures $8 \mathrm{~b}$ and $8 \mathrm{c}$ show that both sectors face similar bankruptcy rates. The similar need of credit in order to finance R\&D is visible in figures $8 \mathrm{e}$ and $8 \mathrm{f}$ while figures $8 \mathrm{~g}$ and $8 \mathrm{~h}$ show that also the credit needed in order to repay old debt is similar and at a low level. The high tech sector is constrained in its growth because credit is shifted away to the low tech sector. If the bank puts all weight on sector specific issues the bankruptcy rate information will exert its equalizing effect to the maximum extent. If the bank puts weight on profitability only it does react on the different levels of profitability between the high tech and the low tech sector. Figure 9 shows that the high tech sector is able to fully benefit from its inherent advantage of a higher probability of innovating and imitating. It grows very fast (figure 9a). The low tech sector hardly grows as all the high tech firms are more profitable as the low tech firms and hence the low tech sector has not much access to credit. Figures $9 b$ and $9 c$ indicate that in both sectors 


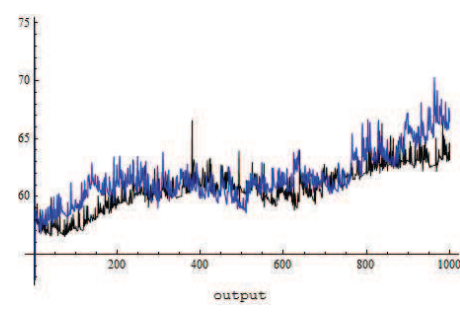

(a) output

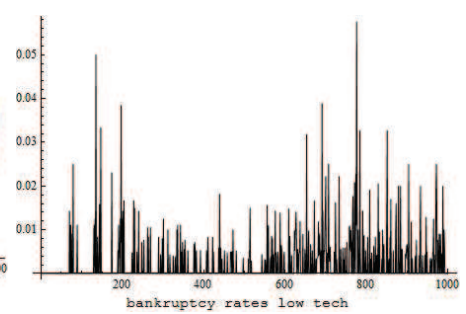

(b) bankruptcy rate low tech

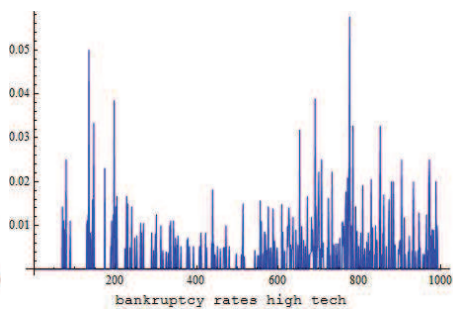

(c) bankruptcy rate high tech
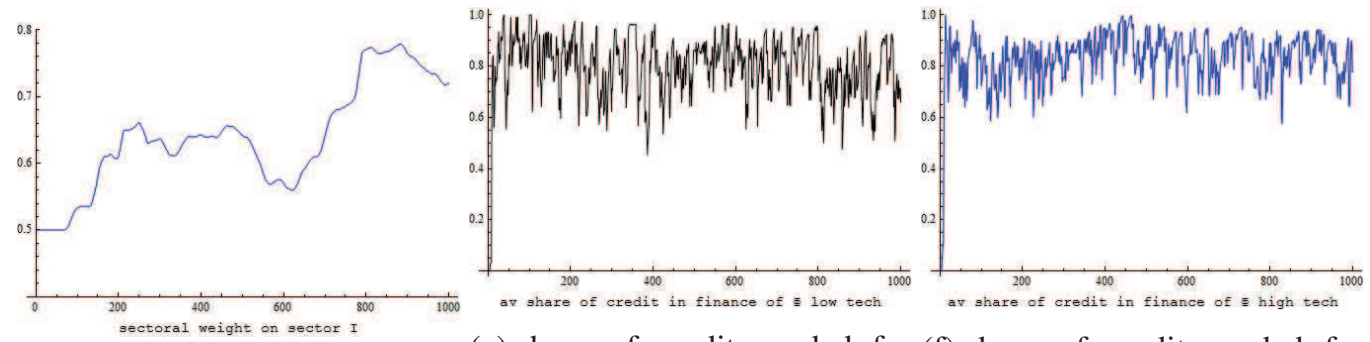

(d) $\lambda^{s}$

(e) share of credit needed for (f) share of credit needed for R\&D low tech R\&D high tech

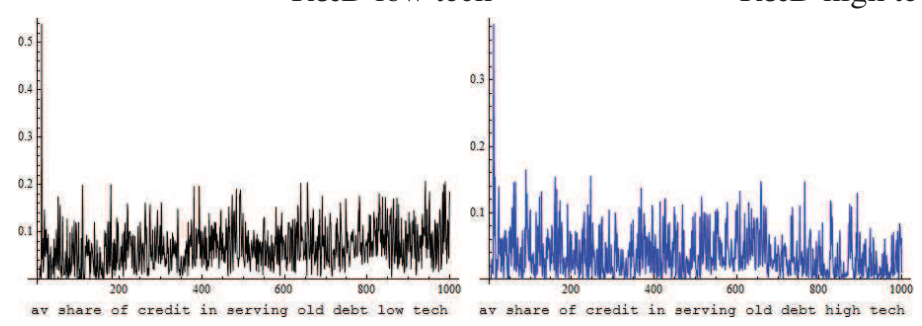

(g) share of credit needed for $(\mathrm{h})$ share of credit needed for serving old debt low tech serving old debt high tech

Figure 8: Over time dynamics for $\lambda=0$ (Blue $\rightarrow$ high-tech sector) 


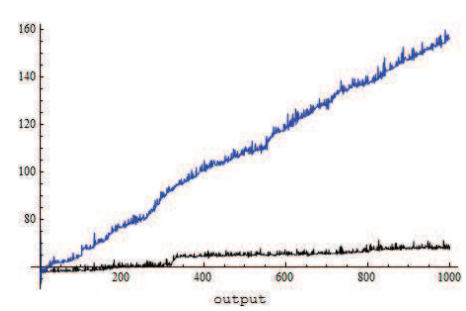

(a) output

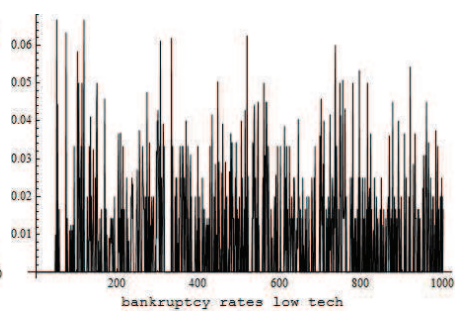

(b) bankruptcy rate low tech

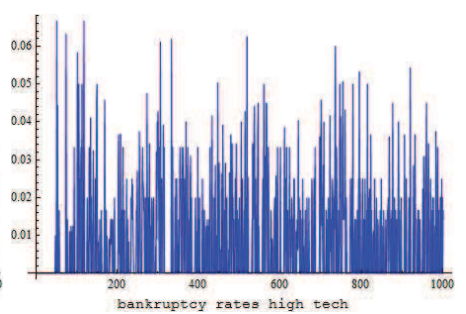

(c) bankruptcy rate high tech
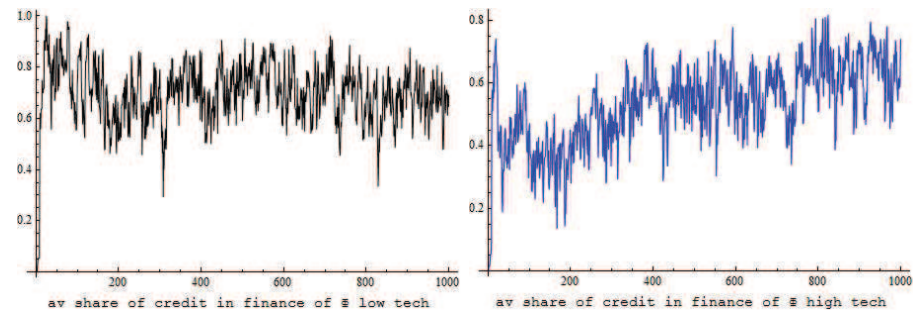

(d) share of credit needed for (e) share of credit needed for R\&D low tech R\&D high tech
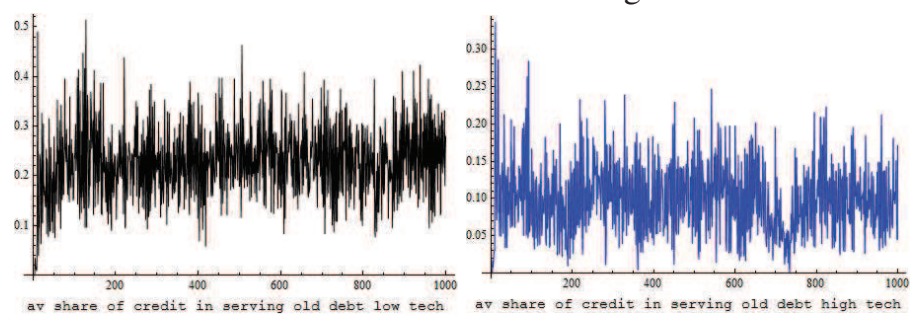

(f) share of credit needed for (g) share of credit needed for serving old debt low tech serving old debt high tech

Figure 9: Over time dynamics for $\lambda=1$ (Blue $\rightarrow$ high-tech sector) 
there are more bankruptcies than in the regime where $\lambda=0$. Furthermore, also the credit needed in financing $R \& D$ is a little bit different. While for the low-tech sector there is no clear difference (figure 9d), the high tech sector is in increasing need of credit for R\&D over time (figure 9e). Additionally, the rate of credit needed to repay old debt is higher for both sectors in this scenario (figures $9 \mathrm{f}$ and $9 \mathrm{~g}$ ). The equalizing impact of the bankruptcy rates is without any effect here. A better technology is not punished due to credit supply in this scenario. The high tech sector benefits from that. The remaining firms will keep up wanting to conduct R\&D which is why the share of credit needed for that increases over time. Both sectors use credit more as it is not shifted away by the bank. Nevertheless, as the high tech sector evolves faster those firms will be allocated most credit due to their high profitability. This is visible in the slow evolution of the low tech sector (figure 9a).

Thus, the bank policy determines to what extent competition will impact credit supply. The more the bank focuses on sector-specific information, that is market-share and risk, first of all, the more similar will the evolution of both sectors be. If the bank does not distinguish between sectors it does not take risk into account and competition across sectors is not important. Then, the more innovative sector will attract most of credit supply because the most innovative firms are much more profitable. Therefore, the high tech sector will be able to evolve much faster while the low-tech sector has hardly any access to credit and thus evolves almost not at all.

In order to check for the robustness of the results a Wilcoxon-Signed-Rank Test is conducted. This non-parametric test is done for the impact of the bank policy under 50 random market and firm policy setups for a significance level of $95 \%$. As market conditions cannot be influenced by the agents in this model, the focus is on policies. Furthermore, since the impact of credit constraints is the matter of interest, the results obtained are checked for robustness by focusing on the bank policy and comparing three levels of it. It is checked whether the results obtained from the comparative analysis hold in broader, randomly chosen parameter setups, that is, in a broader environment. The Wilcoxon-Signed Rank Test confirms the qualitative findings of this section and of the following one as well, so that those are concluded to be robust at a $95 \%$ significance level (see appendix).

\section{Market Outlook - Expectation Formation}

In this section we examine the impact of different kinds of expectation formation by the bank on the evolution of the sectors. The bank chooses how much credit to allocate to each sector by setting $\lambda_{t}^{s}$ according to a mix of financial data and technological growth expectations. Financial data analysis is backward looking. We want to assess the ramifications of rather forward-looking market analyses and whether they have the potential to become self-fulfilling. 
The financial data is covered by the cash flow and the survival rates. Growth expectations aim at forecasting the average productivity of each sector. Expectations are formed by adapting to the history of average productivity levels of the sectors. The variation of a single parameter in the expectation formation rule can yield outcomes for three different mindsets of the bank affecting the rating. By changing this parameter $\beta_{g}$ over a range of negative and positive values, a fundamental view, naive expectations and trend extrapolation are incorporated in the simulation. A fundamental bank view prevails if $\beta_{g}$ is negative. If it is zero, there are naive expectations and for positive values the bank follows the current trend.

The bank first computes the average growth of average productivity in each sector for a particular period $H$. In more detail the average productivity of industry $I$ at period $t$ is

$$
\bar{A}_{I, t}=\frac{\sum_{i \in I} A_{i t} K_{i t}}{\sum_{i \in I} K_{i t}}
$$

The growth rate of average productivity in industry $I$ at period $t$ is

$$
g_{I, t}=\frac{\bar{A}_{I, t}}{\bar{A}_{I, t-1}}-1
$$

The average productivity growth over a period of length $H$, where the current period is included, is then

$$
\Theta_{I, t}=\frac{1}{H} \sum_{h=0}^{H-1} g_{I, t-h}
$$

The bank does not know the productivity of the upcoming period when it is making the credit decision, therefore it forms the expectation

$$
\hat{g}_{t}=g_{t}+\beta_{g}\left(g_{t}-\Theta_{t}\right)
$$

which applies to both sectors the same. If the adjustment speed and strategy parameter $\beta_{g}=0$, the expectation is naive. The larger $\beta_{g}$ is, the more speculative is the nature of the expectation. If $\beta_{g}$ is negative, the bank believes that the growth rate will converge to its long-term average. Here, the term $\Theta_{t}$ can be understood as the moving average of growth rates for the last $D$ periods. Suppose that the bank translates their expectation about sector $I$ into a scoring number $\sigma_{t}^{I}$ according to

$$
\sigma_{I, t}=\frac{1}{1+e^{-\left(\xi \hat{g}_{I, t}\right)}}
$$

with $\xi>0$ and which assures that $\sigma_{t}^{I} \in[0,1]$. This has advantages for comparing it with the impact of the survival rates which are also between zero and one. Then, the new allocation 
rule is

$$
\lambda_{t}^{s}=\operatorname{Min}\left[1, \operatorname{Max}\left[0, \lambda_{t-1}^{s}+a_{\lambda}\left(R_{I, t-1}-R_{J, t-1}\right)+b_{\lambda}\left(\sigma_{I, t}-\sigma_{J, t}\right)\right]\right]
$$

with $b_{\lambda} \geq 0$.

First, we examine how much of an impact the market outlook may have. We compare different levels of importance between $b_{\lambda} \in[0,1]$ for $\lambda=0.375$ and for a conservative, mean reverting rule of expectations $\beta_{g}=-1$ to illuminate the effect. Results are taken from an interval of $t \in[980,1000]$ and 100 repetitions. Figure 10 shows the result for the experiment

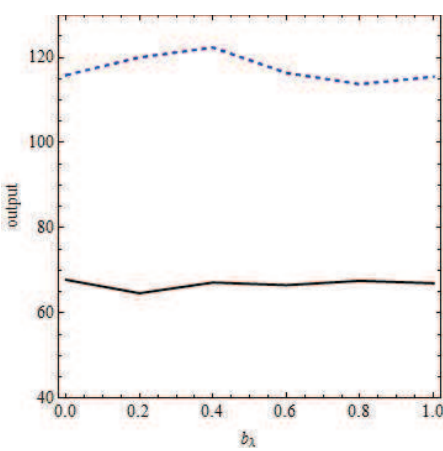

(a) sectoral output

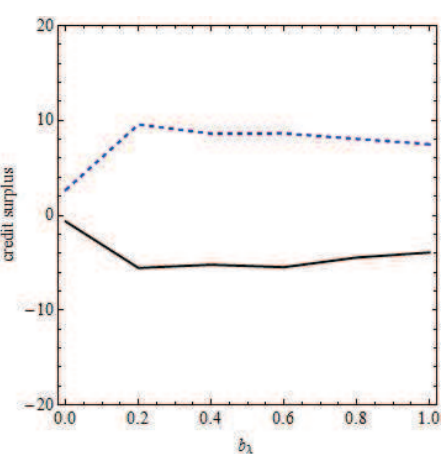

(b) credit surplus

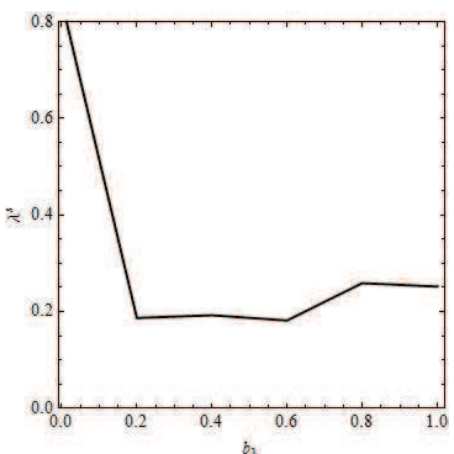

(c) sectoral credit allocation

Figure 10: Impact of market outlook

about the importance of the market outlook. Figure 10a shows that the output for the high tech sector increases as the bank would put more emphasis on the market outlook while the low-tech sector would suffer from a little less output. The reason for the effect on output is visible in figure $10 \mathrm{~b}$ which indicates that for the high-tech sector there will be an increasing amount of credit surplus while at the same time, credit surplus for the low tech sector will be even more negative. The ability to produce output is directly linked to access to credit. Figure 10c indicates the reason for the evolution of credit surplus. The allocation of credit is more in favour for the high-tech sector as the market outlook gains importance.

This impact can actually lead to the effect that the high-tech sector will have more access to credit while without taking market outlook into account it would not have at all. The impact on credit supply reveals this very clearly: for market outlook not taken into account at all $\left(b_{\lambda}=0\right)$, the low tech sector has no surplus or shortage of credit while the high-tech sector suffers from a clear shortage. The importance of market outlook drives a wedge into credit surplus at the expense of the low-tech sector because the bank shifts credit to the high-tech sector. This is a reinforcing effect since more credit means also a higher likelihood of innovating which in return means better a market outlook.

We now ask what impact the kind of expectation formation by the banking sector has. 
Recall that it may have conservative expectations closely related to the long-term average or that expectations may be formed in a trend-extrapolation fashion. We use $\xi=400$ and $b_{\lambda}=0.35$. The time span is again covered until $T=1000$. The experiment is conducted for $\beta_{g} \in[-1,2]$.

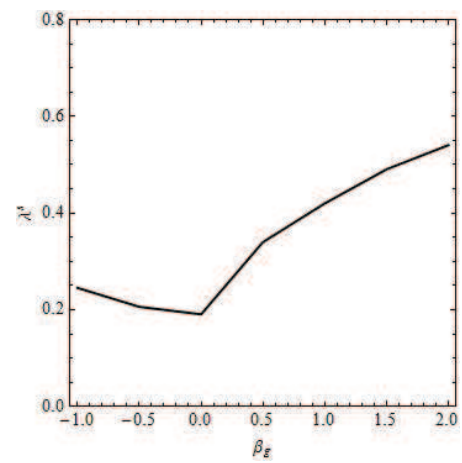

(a) sector parameter

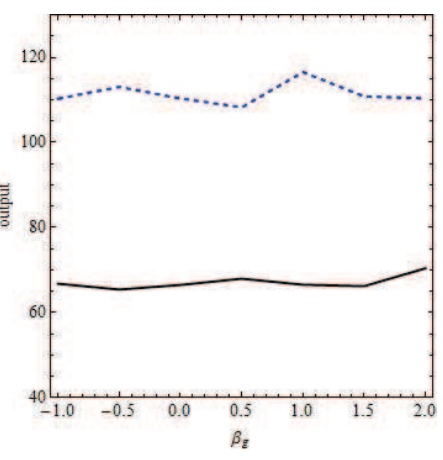

(b) output

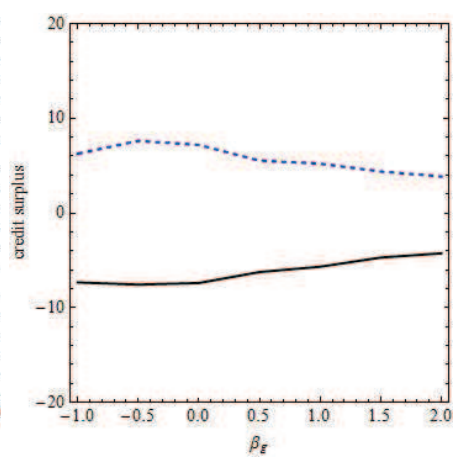

(c) credit surplus

Figure 11: Impact of extrapolation of banks

Figure 11 shows how the expectational mindset of the bank impacts the economy in the long run. Results reveal that the way expectations are formed does have an impact on the credit decision (figure 11a) but the impact on economic variables is meager (figures 11b). Credit surplus seems to increase for the low tech sector and to decrease for the high tech sector, but the scale is very small (figure 11c). Extrapolating the technological progress does lead, however, to less credit being supplied to the innovative sector (figure 11a). The reason is that increased expectations and increased credit supply for a sector does lead to higher output and better technology. It also is followed by increased competition and industry exits. These exits have a negative impact on further credit supply which is hence shifted away from the innovative sector. Thus, if the bank takes the survival rates into account it is unlikely that even very optimistic expectations lead to more credit supply for the sector in the long run.

The figures 12 and 13 show the differences in dynamics over time for mean-reverting expectations (figure 12) and for extrapolating ones (figure 13). They illustrate the average of 10 repetitions of the simulation. The scoring points difference for expectations is visible in figures $12 b, 12 c$ and $13 b, 13 c$. If the bank has mean-reverting expectations this has a much longer lasting impact on scoring because the average growth matters more than short term deviations. Also, the scores are usually above the threshold of 0.5 . Furthermore, if deviations are extrapolated this works also the other way round after high growth rates due to innovation are not sustained in the following periods. The long lasting scoring impact drives market specific credit supply towards the high-tech sector (12d).

If the bank has extrapolative expectations its judgment is much more volatile and short-lived. 


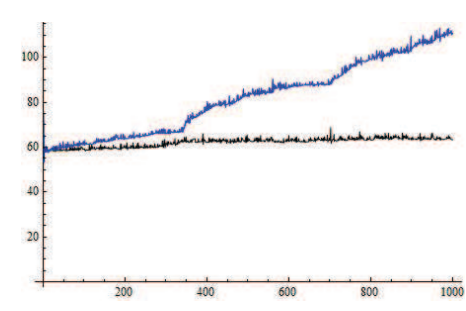

(a) output

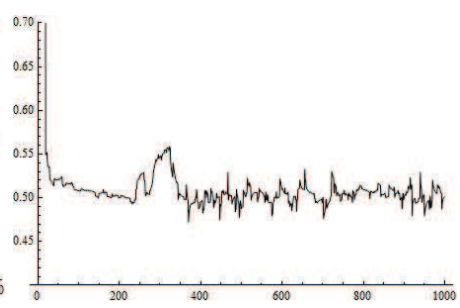

(b) score low tech

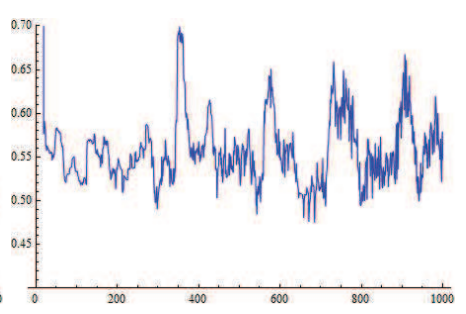

(c) score high tech

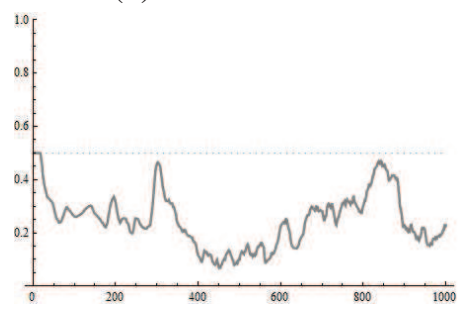

(d) $\lambda^{s}$

Figure 12: Over time dynamics for mean-reverting expectations (Blue $\rightarrow$ high-tech sector)

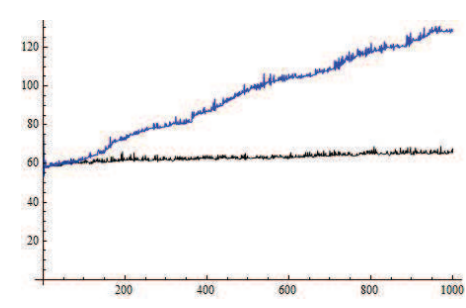

(a) output

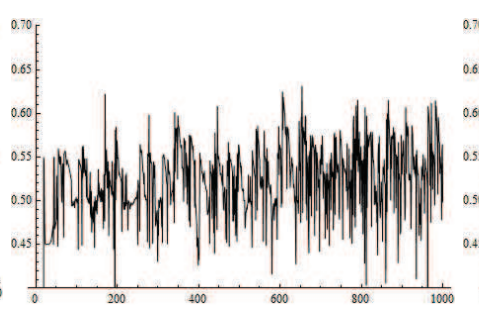

(b) score low tech

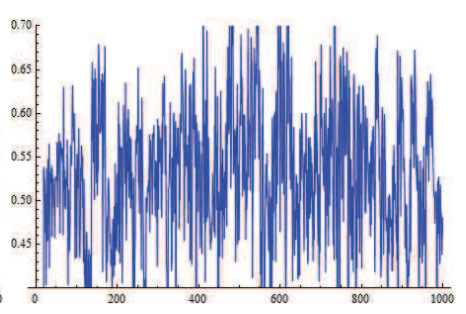

(c) score high tech

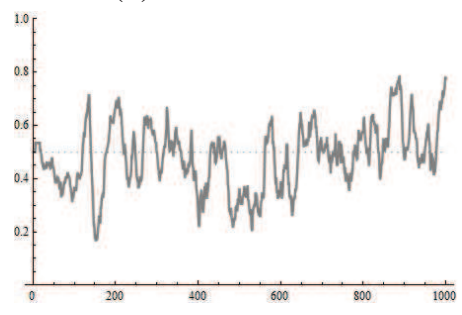

(d) $\lambda^{s}$

Figure 13: Over time dynamics for extrapolative expectations (Blue $\rightarrow$ high-tech sector) 
Because growth expectations are both, highly positive and severely negative, the overall impact on $\lambda^{s}$ is volatile and the parameter is slightly increasing, under huge fluctuations (figure 13d). Therefore, the impact of the survival rate is of higher weight than the market outlook and $\lambda^{s}$ tends to shift credit to the low-tech sector over time more distinctly for $\beta_{g}>0$. If the bank follows mean-reverting expectations scoring differences last longer and technology improvements have a longer lasting impact on $\lambda^{s}$. Therefore, the high-tech sector benefits more from that as a larger share of credit is allocated to this sector (figures 12a and 13a).

Only mean-reverting expectations have the potential to offset the impact of bankruptcy rates. If expectations change too quickly as in trend extrapolating scenarios there is no lasting expectation that can cope with increasing bankruptcy rates. The positive expectations of the high tech sector are just not lasting long enough to exert a positive impact over the bankruptcies triggered by competition and therefore fast changing expectations have not a distinct effect.

Although the impact of expectations is quite visible in $\lambda^{s}$, the composition of the creditworthiness judgment is such that the impact of expectations does not overshadow financial rating. The robustness check reveals that the impact on $\lambda^{s}$ is indeed not robust (see table 3 on page 38). Variations in other parameters therefore matter a lot. In practice, financial rating accounts for fifty to eighty-five percent of the rating outcome (Everling et al., 2009, p. 234). Therefore, there is a visible but not significant impact of the expectations for economic outcomes, such as output or market power in this model. Also, in reality the impact of expectations on the long term economic pattern can be expected to be limited as far as credit rating is concerned.

\section{Concluding Remarks}

In this paper we addressed the question which role bank routines play in the pace of innovation in an economy. We focused on rating rules that impact two different sectors via credit supply by constraining firms in investment and R\&D. In particular, technological progress enhances productivity and output in a sector but also competition so that an increasing number of firms may exit the industry. If the increase in productivity of the surviving firms is too low to compensate for the loss of production by exiting firms, sectoral output decrease in average productivity of a sector.

We build on an evolutionary model where firms in each sector compete by their productivity. They choose how much they invest and how much to spend on R\&D on top of investment. $R \& D$ spending depends positively on the profit history. Both sectors feed back to each other, as well as do single firms, via credit supply. The supplier provides credit according to a rating rule and therefore firms might be constrained. We examine the impact of rating behaviour by addressing two aspects. First, the importance a bank adjoins to either profitability or 
sector-specific information. Secondly, how expectation formation affects the credit supply. Within the credit supply decision there are also contrary effects. The bank assesses the prospects of any firm relative to its rivals. An individual firm may have good prospects but if the prospects of the sector, for instance the survival rate, are low due to increased competition the firm might be constrained in credit nevertheless.

Both aspects of the bank decision have a decisive role in a rating process that takes the sectoral risk from competition into account. As a sectoral average productivity increases more firms in that sector go bankrupt at the same time. Both, the weight and the way the bank forms expectations can influence the impact of the rating procedure. The weight parameter simply determines the impact that risk can exert on the rating decision. If the bank focuses on cash-flow (financial information) the high-tech sector evolves much differently than the low tech sector. It benefits much from its inherent advantages of a higher ability of finding new technology. The low tech sector suffers from that success as the high-tech sector will absorb almost all the credit supply.

The expectation formation of the bank is able to counterbalance the impact of the risk assessment. If the bank has mean-reverting expectations it keeps up expecting a good evolution of the high-tech sector for an extended period. This leads to a persistent shift of credit to the high-tech sector. If the bank has extrapolative expectations it follows upswings and downswings in the average productivity. Therefore there is no persistent force that can outbalance the impact of the higher risk in the high-tech sector. Therefore, credit is shifted gradually to the low tech sector and differences between sectors are less pronounced. 


\section{References}

[1] Achleitner, Ann-Kristin, Oliver Everling and Karl A Niggemann (Eds.) (2007): Finanzrating (Financial Rating), Gabler, Wiesbaden.

[2] Aghion, Philippe, George-Marios Angeletos, Abhijit Banerjee, and Kalina Manova (2005): "Volatility and Growth: Credit Constraints and Productivity-Enhancing Investment", NBER Working Paper No. 11349.

[3] Aghion, Philippe, Philippe Askenazi, Nicolas Berman, Gilbert Cette, and Laurent Eymard (2012): "Credit constraints and the cyclicality of R\&D investment: Evidence from France", Paris School of Economics Working Paper.

[4] Altman, Edward I and Anthony Saunders (1998): "Credit risk measurement: Developments over the last 20 years", Journal of Banking \& Finance, Vol. 21, pp. 1721-1742.

[5] Ben-Zion, Uri (1984): "The R\&D and Investment Decision and Its Relationship to the Firm's Market Value: Some Preliminary Results", in Griliches, Z. (Ed.) R\&D, Patents, and Productivity , pp. 299-314, University of Chicago Press.

[6] Bottazzi, Giulio, Giovanni Dosi, Nadia Jacoby, Angelo Secchi and Federico Tamagni (2010): "Corporate performances and market selection: some comparative evidence", Industrial and Corporate Change, dtq 063.

[7] Bottazzi, Giulio, Angelo Secchi and Federico Tamagni (2006): "Financial fragility and growth dynamics of Italian business firms", LEM WP, No. 2006/07.

[8] Bottazzi, Giulio, Angelo Secchi and Federico Tamagni (2014): "Financial constraints and firm dynamics", Small Business Economics, Vol. 42, pp. 99-117.

[9] Brown, James R, Steven M Fazzari, and Bruce C Petersen (2009): "Financing Innovation and Growth: Cash Flow, External Equity, and the 1990 R\&D Boom", The Journal of Finance, Vol. 64 (1), pp. 151-185.

[10] Brown, James R, Gustav Martinson, and Bruce C Petersen (2012): "Do financing constraints matter for R\&D?", European Economic Review, Vol. 56, pp. 1512-1529.

[11] Canepa, Alessandra and Paul Stoneman (2008): "Financial constraints to Innovation in the UK: Evidence from CIS2 and CIS3", Oxford Economic Papers, Vol. 60, pp. 711-730.

[12] Centre for Strategy and Evaluation Services (2014): Evaluation of Market Practices and Policies on SME Rating, Final Report, available at: http://ec.europa.eu/ enterprise/policies/finance/index_en.htm, accessed November 18, 2014.

[13] Colombo, Luca, Herbert Dawid, and Kordian Kabus (2012): "When do thick venture capital markets foster innovation? An evolutionary analysis", Journal of Evolutionary Economics, Vol. 22, pp. 79-108. 
[14] Crouhy, Michel, Dan Galai, and Robert Mark (2000): "A comparative analysis of current credit risk models", Journal of Banking and Finance, Vol. 24, pp. 59-117.

[15] Czarnitzki, Dirk and Hanna Hottenrott (2011): "R\&D investment and financing constraints of small and medium-sized firms", Small Business Economics, Vol. 36, pp. 65-83.

[16] Dawid, Herbert and Marc Reimann (2004): "Evaluating Market Attractiveness: Individual Incentives Versus Industry Profitability", Computational Economics, Vol. 24, pp. 321-355.

[17] Deutsches Institut für Wirtschaftsforschung (2009): "Wirtschaftsstrukturen und Produktivität im internationalen Vergleich" (Economic Structures and Productivity in an International Comparison), Studien zum deutschen Innovationssystem, No. 2-2009.

[18] Dosi, Giovanni, Giorgio Fagiolo, Mauro Napoletano, Andrea Roventini, and Tania Treibich (2011): Economic Policies with Endogenous Innovation and Keynesian Demand Management, available under http://www.nccert.biz/badania/ konferencje/2011/dsge/files/Economic.pdf, accessed Jan. 29, 2014.

[19] European Commission (2011): "An action plan to improve access to finance for SMEs", European Commission Communication, COM(2011)870.

[20] European Parliament (2006): “Directive 2006/48/EC of the European Parliament and of the Council of 14 June 2006 relating to the taking up and pursuit of the business of credit institutions", Official Journal of the European Union, No. L177/96.

[21] Everling, Oliver, Klaus Holschuh and Jens Leker (Eds.) (2009): Credit Analyst, Oldenbourg, Munich.

[22] Fagerberg, Jan, and Bart Verspagen (2002): "Technology-gaps, innovation-diffusion and transformation: an evolutionary interpretation", Research Policy, Vol 31, pp. 12911304.

[23] Freel, Mark S (2007): "Are Small Investors Credit Rationed?", Small Business Economics, Vol. 28, pp. 23-35.

[24] Giudici, Giancarlo and Stefano Pateari (2000): "The Provision of Finance to Innovation: A Survey Conducted Among Italian Technology-Based Small Firms", Small Business Economics, vol. 14 (1), pp. 37-53.

[25] Guiso, Luigi (1998): "High-tech firms and credit rationing", Journal of Economic Behavior and Organization, Vol. 35, pp. 39-59.

[26] Hall, Bronwyn $\mathbf{H}$ and Josh Lerner (2009): The Financing of R\&D and Innovation, NBER Working Paper.

[27] Hao, Kenneth $\mathbf{Y}$ and Adam B Jaffe (1993): "Effect of liquidity on firms' R\&D spending", Economics of Innovation and New Technology, Vol. 2 (4), pp. 275-282. 
[28] Huang, Haizhou and Changgang Xu (1999): "Institutions, Innovations, and Growth", American Economic Review, Vol. 89 (2), pp. 438-444.

[29] Hyytinen, Ari and Otto Toivanen (2003): "Do financial constraints hold back innovation and growth? Evidence on the role of public policy", ETLA discussion papers, No. 820 .

[30] Kremer, Eduard and Wolfgang ten Hoevel (1989): Kredite an Unternehmen: Kreditentscheidung unter dynamischen Aspekten (Corporate Credit: Credit Decision Under Dynamic Aspects), 2nd edition, Deutscher Sparkassenverlag, Stuttgart.

[31] Lee, Jeho and J Richard Harrison (2001): "Innovation and Industry Bifurcation: the Evolution of R\&D Strategy", Industrial and Corporate Change, Vol. 10 (1), pp. 117-149.

[32] Mancusi, Maria L and Andrea Vezzuli (2010): "R\&D, Innovation and Liquidity Constraints", CONCORD 2010 Conference, Sevilla, 3-4 March 2010.

[33] Marsili, Orietta and Bart Verspagen (2002): "Technology and the dynamics of industrial structures: an empirical mapping of Dutch manufacturing", Industrial and corporate change, Vol. 11, No. 4, pp. 791-815.

[34] Mina, Andrea, Henry Lahr and Alan Hughes (2013): "The Demand And Supply of External Finance for Innovative Firms", Industrial and Corporate Change, Vol. 22, No. 4, pp.869-901.

[35] Mohnen, Pierre A, Franz Palm, Sybrand van der Loeff, and A Tiwari (2008): Financial constraints and other obstacles: are they a threat to innovation activity?, CESifo Working Paper, No. 2204.

[36] Nelson, Richard R and Sidney G Winter (1982): An Evolutionary Theory of Economic Change, Belknap, Cambrigde (MA).

[37] Piga, Claudio A and Gianfranco Atzeni (2007): "R\&D Investment, Credit Rationing and Sample Selection", Bulletin of Economic Research, Vol. 59 (2), pp. 149-178.

[38] Reichling, Peter, Daniela Bietke, and Antje Henne (2003): Praxishandbuch Risikomanagement und Rating (Practical Handbook Risk Management and Rating), 2nd edition (2007), Gabler, Wiesbaden.

[39] Savignac, Frédérique (2008): "Impact of financial constraints on innovation: What can be learned from a direct measure?", Economics of Innovation and New Technology, 17(6), 553-569.

[40] Sheskin, David J (2011): Handbook of parametric and nonparametric statistical procedures, 5th edition, CRC Press, Boca Raton.

[41] Standard and Poor's (2011): "Principles Of Credit Ratings", Global Credit Portal, published February 16, 2011, available at http://www.standardandpoors. $\mathrm{com} / \mathrm{spf} /$ upload/Ratings_EMEA/PrinciplesOfCreditRatings.pdf, accessed December 4, 2014. 
[42] Takalo, Tuomas and Tanja Tanayama (2010): "Is there need for R\&D subsidies?". The Journal of Technology Transfer, Vol. 35 (1), pp. 16-41.

[43] Winter, Sidney G (1984): "Schumpeterian Competition in Alternative Technological Regimes", Journal of Economic Behavior \& Organization, Vol. 5, pp. 287-320.

[44] Yildizoglu, Murat (2002): "Competing R\&D Strategies in an Evolutionary Industry Model", Computational Economics, Vol. 19, pp. 51-65. 


\section{Parameters and Variables}

\begin{tabular}{|l||r||r|}
\hline Parameters & & \\
\hline \hline Demand low-tech sector & $D_{I}$ & 40 \\
Demand high-tech sector & $D_{J}$ & 40 \\
Effectivity of imitation effort low-tech sector & $a_{I}^{i m}$ & 0.02 \\
Effectivity of innovation effort low-tech sector & $a_{I}^{i m}$ & 0.007 \\
Effectivity of effort high-tech sector & $a_{J}^{i m}$, in & $1.2 \cdot a_{I}^{i m, i n}$ \\
Effectivity of effort low-tech sector & $b_{I}^{R D}$ & 0.002 \\
Effectivity of effort high-tech sector & $b_{J}^{R D}$ & $1.2 \cdot b_{I}^{R D}$ \\
Adaptation speed for sector-specific credit due to survival rates & $a_{\lambda}$ & 0.5 \\
Adaptation speed for sector-specific credit due to technol. change & $b_{\lambda}$ & 0.25 \\
initial no. of firms & & 10 \\
initial capital & $K_{i t}^{0}$ & 100 \\
initial technology & $A_{i t}^{0}$ & 0.15 \\
interest rate & $i$ & 0.05 \\
initial R\&D spending desire & $\Phi_{i t}^{0}$ & 0.004 \\
firms' R\&D adjustment policy parameter & $\lambda^{F}$ & 2 \\
depreciation rate & $\delta$ & 0.03 \\
production costs & $c$ & 0.16 \\
lower capital barrier for bankruptcy & $c r i t$ & 1 \\
time horizon for profit history & $T$ & 3 \\
time horizon for productivity history & $\xi$ & 20 \\
markup parameter for investment desire & $\xi$ \\
parameter for scoring points & 400 \\
\hline
\end{tabular}

\begin{tabular}{|l||r||r|}
\hline Control Parameters - basic values & & \\
\hline \hline average credit supply in unit of capital & $l_{t}^{s}$ & 0.05 \\
bank's weighing parameter for credit offer & $\lambda$ & 0.375 \\
\hline
\end{tabular}

\section{Robustness Check}

In order to check whether the results are robust, a Wilcoxon Signed Rank test is conducted. The Wilcoxon Signed Rank test is performed because it allows for testing samples where a normal distribution cannot be assumed and where the variance is unknown. It is a non parametric test. The following procedure is as described by Sheskin. ${ }^{5}$ Basically, the test is whether the medians of two sample populations (data sets) are likely to be the same at a

\footnotetext{
${ }^{5}$ See Sheskin 2011, pp. $245 \mathrm{ff}$.
} 
certain level of significance. If so, the two sample populations can be assumed to be drawn from the same distribution. Some assumptions are essential for the test:

1. The observed data either constitute a random sample of $N$ independent pairs of items.

2. The observed data are measured at a higher level than the ordinal scale.

3. The distribution of the population of difference scores between repeated measurements of between matched items of individuals is approximately symmetric.

The Null-hypothesis is that the two populations which the results stem from do not differ in their median $v: H_{0}: v_{1}=v_{2}$ while the alternative is for a two tailed test $H_{a l t}: v_{1} \neq v_{2}$. that is, the median of population 2 is either below or above the median of population 1 . The results are checked for a significance level of $95 \%$, that is $\alpha=0.05$. Each pair of data is compared and the difference taken $W_{i}=x_{1 i}-x_{2 i}$ for all $i=1, \ldots, N$. Zero differences $W_{i}=0$ are discarded and the sample size left is $n$. Since a two tailed test is conducted, the test statistics is the minimum of the sums of negative and positive differences in the pairs of the samples,

$$
W:=\operatorname{Min}\left[\left|W_{-}\right|, W_{+}\right]
$$

If the sample size is sufficiently large, $W$ can be assumed to be normally distributed. Then, a $z$-value can be computed using the number of nonzero differences $n$. This can also be done for the continuation of data in order to better compare the continuous normal distribution with discrete data in the form

$$
z=\frac{\left|W-\frac{n(n+1)}{4}\right|-0.5}{\sqrt{\frac{n(n+1)(2 n+1)}{24}}} .
$$

In this test, the $H_{0}$ hypothesis can be rejected if $|z| \geq z^{\text {crit }}$ where $z^{\text {crit }}$ is the critical value at a significance level chosen according to a table. For a significance level $\alpha=0.05$ the critical value is $z^{\text {crit }}=1.645$.

The intervals that the parameters for the test are chosen from are: The following tables depict the result of the Wilcoxon Signed Rank test for 100 random samples of above parameter space. If the Null Hypothesis cannot be rejected, " $n s^{\prime \prime}$ is depicted. If it can be rejected, then the direction of difference between sample medians is shown. Where $*$ is depicted, there is no debt to be repaid because credit supply is zero and thus there is no test for that particular case. 


\begin{aligned} & \hline$\delta \in[0.027,0.033] \\ & c \in[0.144,0.176] \\ & a_{I}^{i m} \in[0.018,0.022] \\ & a_{I}^{i n} \in[0.0063,0.0077] \\ & b_{I}^{R D} \in[0.0018,0.0022] \\ & a_{J}^{i m} \in[0.0216,0.0264] \\ & a_{J}^{i n} \in[0.00756,0.00924] \\ & b_{J}^{R D} \in[0.00216,0.00264] \\ & \varphi \in[2.7,3.3] \\ & \lambda^{F} \in[1.8,2.2] \\ & a_{\lambda} \in[0.45,0.55] \\ & b_{\lambda} \in[1.8,2.2] \\ & D_{I} \in[35,45] \\ & D_{J} \in[35,45] \\ & \lambda_{\text {ini }}^{s} \in[0.45,0.55] \\ &$\hline\end{aligned}

Table 1: Parameter space for the robustness check 


\section{Low Tech Sector}

\begin{tabular}{|l||l|l|}
\hline credit supply & output. & credit surpl. \\
\hline
\end{tabular}

$\lambda=0$ vs. $\lambda=0.5$
\begin{tabular}{|l||c|c|}
\hline$b_{\lambda}=0$ & $n s$ & $n s$ \\
$b_{\lambda}=0.25$ & $<$ & $<$ \\
$b_{\lambda}=0.5$ & $<$ & $<$ \\
\hline
\end{tabular}

$\lambda=0.5$ vs. $\lambda=1$
\begin{tabular}{|l||c|c|}
$\lambda=0$ & $<$ & $<$ \\
$b_{\lambda}=0$ & $n s$ & $<$ \\
$b_{\lambda}=0.25$ & $n s$ & $<$ \\
$b_{\lambda}=0.5$ & $n s$ & $<$ \\
\hline
\end{tabular}

$\lambda=0$ vs. $\lambda=1$
\begin{tabular}{|l||l|l|}
$\lambda=1$ & $<$ & $<$ \\
$b_{\lambda}=0$ & $<$ & $<$ \\
$b_{\lambda}=0.25$ & $<$ & $<$ \\
$b_{\lambda}=0.5$ & $<$ & $<$ \\
\hline
\end{tabular}

\section{High Tech Sector}

\begin{tabular}{|l||l|l|}
\hline credit supply & output & credit surpl. \\
\hline
\end{tabular}

$\lambda=0$ vs. $\lambda=0.5$
\begin{tabular}{|l||c|c|}
\hline$b_{\lambda}=0$ & $n s$ & $n s$ \\
$b_{\lambda}=0.25$ & $<$ & $<$ \\
$b_{\lambda}=0.5$ & $n s$ & $n s$ \\
\hline
\end{tabular}

$\lambda=0.5$ vs. $\lambda=1$
\begin{tabular}{|l||c|l|}
\hline$b_{\lambda}=0$ & $<$ & $<$ \\
$b_{\lambda}=0.25$ & $n s$ & $<$ \\
$b_{\lambda}=0.5$ & $n s$ & $<$ \\
\hline
\end{tabular}

$\lambda=0$ vs. $\lambda=1$
\begin{tabular}{|l||c|c|}
\hline$b_{\lambda}=0$ & $<$ & $<$ \\
$b_{\lambda}=0.25$ & $<$ & $<$ \\
$b_{\lambda}=0.5$ & $<$ & $n s$ \\
\hline
\end{tabular}

Table 2: Results of the Wilcoxon-Signed-Rank Test for the bank policy 
Low Tech Sector

\begin{tabular}{|l||l|l|l|}
\hline credit supply & output & credit surpl. & $\lambda^{s}$ (both sectors) \\
\hline
\end{tabular}

$\beta_{g}=-1$ vs. $\beta_{g}=0$
\begin{tabular}{|l||l|l|l|}
\hline$b_{\lambda}=0$ & $n s$ & $n s$ & $n s$ \\
$b_{\lambda}=0.25$ & $n s$ & $n s$ & $n s$ \\
$b_{\lambda}=0.5$ & $n s$ & $n s$ & $n s$ \\
\hline
\end{tabular}

$\beta_{g}=0$ vs. $\beta_{g}=2$
\begin{tabular}{|l||l|l|l|}
\hline$b_{\lambda}=0$ & $n s$ & $n s$ & $n s$ \\
$b_{\lambda}=0.25$ & $n s$ & $n s$ & $n s$ \\
$b_{\lambda}=0.5$ & $n s$ & $n s$ & $n s$ \\
\hline
\end{tabular}

$\beta_{g}=-1$ vs. $\beta_{g}=2$

\begin{tabular}{|l||c|l|l|}
\hline$b_{\lambda}=0$ & $n s$ & $n s$ & $n s$ \\
$b_{\lambda}=0.25$ & $>$ & $n s$ & $n s$ \\
$b_{\lambda}=0.5$ & $n s$ & $n s$ & $n s$ \\
\hline
\end{tabular}

High Tech Sector

\begin{tabular}{|l||l|l|}
\hline credit supply & output & credit surpl. \\
\hline
\end{tabular}

$\beta_{g}=-1$ vs. $\beta_{g}=0$
\begin{tabular}{|l||l|l|}
\hline$b_{\lambda}=0$ & $n s$ & $n s$ \\
$b_{\lambda}=0.25$ & $n s$ & $n s$ \\
$b_{\lambda}=0.5$ & $n s$ & $n s$ \\
\hline
\end{tabular}

$\beta_{g}=0$ vs. $\beta_{g}=2$
\begin{tabular}{|l||c|c|}
\hline$b_{\lambda}=0$ & $n s$ & $<$ \\
$b_{\lambda}=0.25$ & $n s$ & $n s$ \\
$b_{\lambda}=0.5$ & $n s$ & $n s$ \\
\hline
\end{tabular}

$\beta_{g}=-1$ vs. $\beta_{g}=2$
\begin{tabular}{|l||l|l|}
\hline$b_{\lambda}=0$ & $n s$ & $n s$ \\
$b_{\lambda}=0.25$ & $n s$ & $n s$ \\
$b_{\lambda}=0.5$ & $n s$ & $n s$ \\
\hline
\end{tabular}

Table 3: Results of the Wilcoxon-Signed-Rank Test for the expectation formation 